\title{
Inhibitory control as a mediator of bidirectional effects between early oppositional behavior and maternal depression
}

\author{
DANIEL EWON CHOE ${ }^{\mathrm{a}}$, DANIEL S. SHAW ${ }^{\mathrm{b}}$, LAURETTA M. BRENNAN ${ }^{\mathrm{a}}$, THOMAS J. \\ DISHION ${ }^{\mathrm{b}}$, MELVIN N. WILSON ${ }^{\mathrm{c}}$ \\ aUniversity of Pittsburgh \\ ${ }^{\mathrm{b}}$ Arizona State University \\ cUniversity of Virginia
}

\section{Abstract}

Maternal depression is an established risk factor for child conduct problems, but relatively few studies have tested whether children's behavioral problems exacerbate mothers' depression or whether other child behavioral characteristics (e.g., self-regulation) may mediate bidirectional effects between maternal depression and child disruptive behavior. This longitudinal study examined the parallel growth of maternal depressive symptoms and child oppositional behavior from ages 2 to 5; the magnitude and timing of their bidirectional effects; and whether child inhibitory control, a temperament-based self-regulatory mechanism, mediated effects between maternal depression and child oppositionality. A randomized control trial of 731 at-risk families assessed children annually from ages 2 to 5 . Transactional models demonstrated positive and bidirectional associations between mothers' depressive symptoms and children's oppositional behavior from ages 2 to 3 , with a less consistent pattern of reciprocal relations up to age 5 . Mediation of indirect mother-child effects and child evocative effects depended on the rater of children's inhibitory control. Findings are discussed in regard to how child evocative effects and self-regulatory mechanisms may clarify the transmission of psychopathology within families.

\begin{abstract}
An increasing number of longitudinal studies demonstrate bidirectional associations between maternal depressive symptoms and child conduct problems (Gross, Shaw, \& Moilanen, 2008; Nicholson, Deboeck, Farris, Boker, \& Borkowski, 2011; Raposa, Hammen, \& Brennan, 2011; Shaw, Gross, \& Moilanen, 2009). Following postulations of multiple theorists (Bell, 1968; Sameroff \& Chandler, 1975; Shaw \& Bell, 1993), a transactional framework can help elucidate the interplay between maternal depression and child problem behavior (Connell \& Goodman, 2002; Dodge, 1990). Although negative mother-child interactions are primary mechanisms through which maternal depression reinforces child conduct problems (Du Rocher Schudlich \& Cummings, 2007; Lovejoy, Graczyk, O'Hare, \& Neuman, 2000), few studies explore other child behavioral characteristics that may mediate
\end{abstract}

\footnotetext{
Address correspondence and reprint requests to: Daniel Ewon Choe, Department of Psychology, University of Pittsburgh, 210 South Bouquet Street, 4423 Sennott Square, Pittsburgh, PA 15260; dec60@ pitt.edu.

Supplementary Materials

The Supplementary Materials for this article can be accessed at http://journals.cambridge.org/dpp
} 
bidirectional effects between maternal depression and child disruptive behavior, especially child evocative effects. An important aspect of children's self-regulation is inhibitory control (IC), which is a promising candidate to test as a mediator because of its associations with conduct problems (Martel \& Nigg, 2006; Olson, Sameroff, Kerr, Lopez, \& Wellman, 2005) and maternal distress (Lengua, Bush, Long, Kovacs, \& Trancik, 2008). Early behavioral problems and maternal depression may hinder growth of children's self-regulation, extending their dependency on caregiver support to help manage their behavior when mothers are in a state in which they are less likely to provide it (Goodman \& Gotlib, 1999). Ensuing self-regulatory problems may consequently exacerbate symptoms in both mothers and children. The current study's aims were to clarify bidirectional associations between maternal depressive symptoms and child oppositional behavior in early childhood by exploring their parallel growth, the timing and magnitude of their bidirectional effects, and the mediating role of IC.

\section{Maternal Depression and Child Conduct Problems}

Women of childbearing age and mothers of young children have high prevalence rates of major depressive disorder (Kessler et al., 2003). In a large nationally representative US sample, over $80 \%$ of mothers reported stable levels of low to moderate depressive symptoms when children were 1 month to 7 years old (Campbell, Matestic, von Stauffenberg, Mohan, $\&$ Kirchner, 2007). More serious and/or chronic depressive symptoms characterized a subgroup of mothers whose children had higher frequencies of adjustment problems and whose families were exposed to greater sociodemographic risk factors and poorer motherchild interactions. Both clinical depression and high levels of maternal depressive symptoms are linked to child conduct problems (Cummings, Keller, \& Davies, 2005; Goodman \& Gotlib, 1999; Kouros \& Garber, 2010; Weinfield, Ingerski, \& Moreau, 2009), thus "maternal depression" will be used in reference to studies that measured depression using diagnostic criteria or symptom counts.

Researchers posit that infants and toddlers are more likely to develop conduct problems when exposed to maternal depression than are older children owing to their considerable dependence on caregivers (Bagner, Pettit, Lewinsohn, \& Seeley, 2010; Connell \& Goodman, 2002; Cummings \& Davies, 1994). Because compromised parenting is believed to be one pathway through which maternal depression influences child outcomes (Goodman \& Gotlib, 1999; Lovejoy et al., 2000), it also follows because of the substantial amount of time infants and toddlers spend with their mothers that they would be more affected by maternal depression than older children are. A meta-analysis examining associations between maternal depression and child disruptive behavior found stronger associations in younger children than in older children (Goodman et al., 2011). We considered early childhood a sensitive period of vulnerability to effects of maternal depression and a critical phase in which to examine its interplay with child disruptive behavior.

Despite an established relation in early childhood, bidirectional associations between maternal depression and child conduct problems remain an area of needed research (Goodman et al., 2011; Shaw, Gross, et al., 2009). Gross, Shaw, Burwell, and Nagin (2009) found that low-income toddler boys' disruptive behavior was associated with trajectories of 
persistently high levels of maternal depressive symptoms from early to middle childhood, which in turn predicted boys' antisocial behavior in adolescence. The same mother-son dyads showed bidirectional effects between maternal depression and boys' aggressive behavior from ages 5 to 6 , as well as between maternal depression and boys' antisocial behavior in adolescence (Gross, Shaw, \& Moilanen, 2008). These findings indicate reciprocal associations between maternal depression and youth conduct problems.

\section{A Transactional Framework for Maternal Depression and Child Conduct Problems}

Theorists have elucidated the continuous, reciprocal interplay between children and mothers (Bell, 1968; Belsky, 1984; Sameroff, 2009). Transactional models postulate an ongoing interplay between mother and child in which both are considered active agents who shape development by selecting and eliciting social experiences and modifying their physiological effects through self-regulation (Cicchetti \& Tucker, 1994; Sameroff, 2009). The earliest conceptualizations of a transactional model were autoregressive cross-lagged models (Sameroff, 2009; Sameroff \& Chandler, 1975), but more recently researchers have utilized latent growth curve models to relate changes in mothers' depressive symptoms to changes in children's conduct problems. Both approaches can contribute complementary evidence of bidirectionality.

Variants of latent growth curve (LGC) models indicate a greater likelihood of maternal depression predicting child conduct problems than of child conduct problems predicting mothers' depression. For example, Nicholson et al. (2011) demonstrated that as maternal depression worsened or improved over time so did children's disruptive behavior, but changes in children's disruptive behavior were more strongly related to maternal depression than changes in maternal depression were related to child behavior. In a study examining parallel trajectories of latent change scores in maternal depression and adolescents' disruptive problems, a technique combining parallel process LGC and autoregressive crosslagged modeling, only maternal depression predicted subsequent increases in disruptive behavior (Kouros \& Garber, 2010). Parallel process LGC models can test whether growth in maternal depression and child conduct problems are interrelated, but they typically cannot identify the temporal order of changes (Ferrer \& McArdle, 2010) or time-specific effects of static variables (Bollen \& Curran, 2004), such as whether children's conduct problems at a specific age predict levels of maternal depression at subsequent assessment points.

Autoregressive cross-lagged (ARCL) models can test whether maternal depression and child conduct problems predict higher levels of each other from one age to the next (Gross, Shaw, \& Moilanen, 2008; Shaw, Gross, et al., 2009), which is a major strength of ARCL models because relations between maternal depression and child adjustment problems differ by timing of exposure (Campbell et al., 2007). ARCL models are useful for clarifying the developmental timing and direction of effects between two or more constructs, as well as the mechanisms underlying their associations through tests of mediation. They are, however, limited in focus to lagged and fixed effects as opposed to growth over time, disregarding patterns of change in developmental processes (Ferrer \& McArdle, 2010). Similar to LGC 
models, studies with ARCL models indicate earlier and more consistent effects of maternal depression on child conduct problems than of conduct problems on maternal depression (e.g., Shaw, Gross, et al., 2009).

In this study, we estimated ARCL and LGC models separately to answer distinct research questions about developmental change and bidirectional associations between maternal depression and child oppositional behavior. Our first aim was to elucidate changes in maternal depression and child oppositionality from ages 2 to 5 and relations between their changes in LGC models. We tested associations between changes in maternal and child mental health problems to determine whether their developmental trajectories were interrelated. The second aim was to clarify the developmental timing and direction of fixed effects between maternal depression and child oppositional behavior across ages 2 to 5 in ARCL models. We tested whether maternal and child mental health problems predicted subsequent levels of each other as time-specific bidirectional effects. In sum, we used LGC and ARCL modeling to examine how maternal depression and child oppositional behavior change over time, whether their changes are related, and whether their static levels show bidirectional effects, thus providing complementary tests of their developmental changes and bidirectional interplay.

Although various modeling approaches have indicated earlier and/or more frequent effects of maternal depression on child conduct problems than child evocative effects, this may be due to studies relying on broad definitions of child behavioral problems (e.g., Kouros \& Garber, 2010). Few studies have examined how narrowly defined dimensions of disruptive behavior are associated with maternal depression. Oppositional behaviors that directly challenge parenting efforts might be more problematic for mothers' confidence, selfefficacy, and, ultimately, their well-being than hyperactivity, inattention, or even aggression, which although noxious to parents, occurs with much less frequency than does oppositional behavior during the toddler and preschool years (Keenan \& Shaw, 1994). Oppositional behavior increases intensely during toddlerhood as children's physical mobility improves without the requisite concomitant growth in cognitive abilities to appreciate the consequences of their behavior, resulting in greater parental restrictions and child oppositionality (Shaw \& Bell, 1993). The current study focuses on child oppositional behavior to increase the likelihood of identifying child evocative effects on maternal depression relative to previous research (Gross, Shaw, \& Moilanen, 2008).

Although evidence of reciprocal effects between maternal depression and child conduct problems has accumulated in recent years (Kouros \& Garber, 2010; Nicholson et al., 2011; Raposa et al., 2011), mechanisms underlying their reciprocity remain unclear (Shaw, Gross, et al., 2009). Early temperament studies indicated that young children with regulatory problems often elicited distress in mothers, contributing to views of difficult temperaments as risk factors for both maternal depression (Cummings \& Davies, 1994; Dodge, 1990) and child conduct problems (Deater-Deckard, Dodge, Bates, \& Pettit, 1998). More recently, researchers have linked low levels of child self-regulation with high levels of conduct problems (Martel \& Nigg, 2006; Olson et al., 2005) and maternal distress (Lengua et al., 2008; Sektnan, McClelland, Acock, \& Morrison, 2010). Testing whether children's selfregulation mediates associations between maternal depression and child oppositional 
behavior may clarify the role of self-regulatory deficits in bidirectional associations between symptoms in mothers and children.

\section{The Role of IC}

One component of self-regulation, IC, is defined as the capacity for active, voluntary inhibition, or modulation of behavior (Kochanska, Murray, Jacques, Koenig, \& Vandegeest, 1996). IC overlaps conceptually with inhibition, a core executive function reflecting the ability to ignore distractions and remain focused, and to resist making one response in lieu of another (Diamond, 2006). The ability to inhibit attention to distractors and behavioral impulses promotes selective and sustained attention and flexible behavior; therefore, both inhibition and IC represent volitional control over one's attention and behavior rather than being controlled by external stimuli, emotions, or impulses (Diamond, 2006). An early form of IC, albeit a more passive system of inhibition, emerges late in the first year as some infants begin inhibiting their approach to novel or intense stimuli (Rothbart \& Bates, 1998). Rapid growth in IC occurs during the toddler and preschool years, enabling children to increasingly inhibit impulses and modulate their social conduct (Kochanska, Murray, \& Coy, 1997; Kochanska et al., 1996). Similar growth of IC during early childhood has been observed in both low-risk and high-risk community samples of children, including the current low-income sample (Moilanen, Shaw, Dishion, Gardner, \& Wilson, 2010). Individual differences in IC are moderately stable from toddlerhood to middle childhood and contribute to children's internalization of socially appropriate behavior with broad implications for adjustment across developmental periods for typical and atypical populations (Kochanska et al., 1997; Olson, Schilling, \& Bates, 1999).

Studies show that low levels of child IC are associated with high levels of impulsivity and hyperactivity in middle childhood and conduct problems in adolescence (Olson et al., 1999; Utendale, Hubert, Saint-Pierre, \& Hastings, 2011). Some evidence suggests that developmental changes in children's IC and conduct problems regulate one another over time, such that IC and conduct problems are initially unrelated in toddlerhood but increasingly become inversely related from the preschool to early school years (Utendale \& Hastings, 2011). The majority of young children who demonstrate initially high rates of overt conduct problems show a steep decrease in symptoms from early to middle childhood as part of being socialized (Côté, Vaillancourt, Leblanc, Nagin, \& Tremblay, 2006; Shaw, Gilliom, Ingoldsby, \& Nagin, 2003). This decrease in overt conduct problem is in part related to increases in children's self-regulatory skills, including increases in IC (Kochanska et al., 1997; Moilanen et al., 2010).

Although IC is considered a regulatory component of temperament, correlational and experimental evidence suggests it is a malleable dimension that can be shaped through children's interactions with adults (Greenberg, 2006; Rothbart \& Bates, 1998). Sensitive and responsive caregiving is linked to the optimal development of young children's effortful control, a self-regulatory dimension of temperament defined as the ability to inhibit a dominate response in favor of a less dominant response, in which the most theoretically and empirically related indicators are IC and attentional focusing (Kochanska, Murray, \& Harlan, 2000; Spinrad et al., 2007). Similarly, high levels of parental positive support at age 
2 have been shown to predict faster growth of children's IC from ages 2 to 4 in a previous study of the current sample (Moilanen et al., 2010).

Low levels of children's self-regulation are linked to maternal depression (Gartstein \& Fagot, 2003; Lengua et al., 2008; Sektnan et al., 2010); however, few studies have examined associations among maternal depression, child conduct problems, and IC simultaneously. Early oppositional behavior may hinder gains in children's self-regulation, contributing to difficulties when inhibiting impulses and attending to parents' directives and thereby worsening mothers' depressive symptoms through stressful caregiving experiences with children who increasingly fail to meet expectations of age-appropriate behavior. Goodnessof-fit models of parent-child relationships suggest mothers with depression and children with temperament problems are incompatible social partners (Mangelsdorf, Gunnar, Kestenbaum, Lang, \& Andreas, 1990). Poor mother-child interactions and parenting deficits associated with maternal depression (Campbell et al., 2007; Goodman \& Gotlib, 1999; Lovejoy et al., 2000) suggest offspring with low self-regulation do not receive the necessary support to learn to refrain from inappropriate behavior. Given IC's role in regulating conduct and observed associations between self-regulation and maternal depression, examining its involvement in bidirectional associations between maternal depression and child behavior is warranted. The third aim of this study was to examine whether children's IC mediates associations between maternal depression and their oppositional behavior.

In addition to investigating bidirectional processes with different modeling approaches, the current study's methodological strengths addressed limitations of previous research, such as a sole reliance on mother ratings of their depressive symptoms and children's disruptive behavior, which introduces problems of reporter bias and shared variance from a single informant (Burt et al., 2005). Studies in which mothers rate both their well-being and children's problem behavior tend to produce stronger effects than studies with multiple informants, and mothers with depression may possess biased perceptions of children's behavior (Burt et al., 2005; Goodman et al., 2011). Many studies have also been limited by small samples, retrospective reports, short-term follow-ups, and a lack of a developmental perspective (Campbell et al., 2007; Connell \& Goodman, 2002; Goodman \& Gotlib, 1999), all issues addressed by the current study's methods.

\section{The Current Study}

The current study seeks to elucidate developmental and bidirectional processes involving maternal depression and child oppositional behavior during early childhood by examining their parallel growth from ages 2 to 5 years, relations between their changes over time, timing and direction of effects between their static levels, and whether children's IC mediates their associations. Using a large sample of toddlers followed annually from ages 2 to 5, this prospective longitudinal study included ratings of child oppositional behavior and IC from both mothers and alternative caregivers (e.g., fathers or grandmothers). Because the study included data collected from a randomized control trial involving three types of communities (i.e., urban, rural, and suburban), we accounted for geographic site and intervention status, along with child gender, race, and maternal education level owing to their associations with maternal depression and child problem behavior (Campbell et al., 
2007; Else-Quest, Hyde, Goldsmith, \& Van Hulle, 2006; Gorman-Smith \& Loeber, 2005; Loeber \& Farrington, 2000; Moilanen et al., 2010).

First, we hypothesized that initial levels and growth in maternal depressive symptoms and child oppositional behavior from ages 2 to 5 would be positively correlated. Second, we hypothesized there would be bidirectional effects, such that maternal depression would predict high levels of child oppositionality and vice versa. We expected bidirectionality to be more prominent from ages 2 to 3 than from ages 3 to 4 or 4 to 5, owing to the rapid gains in children's mobility, language, and oppositional behavior during early toddlerhood relative to the preschool period, "gains" that mothers would find more aversive and more likely to worsen their depressive symptoms (Bongers, Koot, van der Ende, \& Verhulst, 2004; Dix, Stewart, Gershoff, \& Day, 2007; Shaw \& Bell, 1993). Levels of oppositional behavior typically decline through childhood (Nagin \& Tremblay, 1999), so their reciprocal associations with maternal depression should be less prominent at older ages as a function of children's decreasing oppositionality and time spent with mothers. Third, based on IC's negative associations with conduct problems and maternal distress and its broad role in adaptive functioning, we hypothesized that low levels of children's IC would mediate associations between maternal depressive symptoms and child oppositional behavior for both mother-to-child effects and child evocative effects.

\section{Method}

\section{Participants}

A sample of 731 mother-child dyads (49.5\% girls) across three US cities participated in a randomized control trial that investigated the prevention of children's behavioral problems and negative parent-child interactions (Dishion et al., 2008). Participants were recruited between 2002 and 2003 from Women, Infants, and Children Nutritional Supplement (WIC) programs in the metropolitan areas of Pittsburgh, Pennsylvania, and Eugene, Oregon, and within and immediately outside of Charlottesville, Virginia. Families with a child between the ages of 2 years and 0 months and 2 years and 11 months were invited to participate depending on whether they met risk criteria in at least two of three risk domains for future behavioral problems: child behavior (e.g., early conduct problems or high-conflict relationships with adults), family problems (maternal depression or daily parenting challenges), and sociodemographic risk (low education achievement and low family income). Families who scored at or above 1 standard deviation above mean scores in these domains met risk criteria for recruitment. Initially, 1,666 families were contacted at WIC sites, 879 met eligibility requirements (52\% in Pittsburgh, 57\% in Eugene, and 49\% in Charlottesville), and 731 families (83.2\%) provided consent and assent (88\% in Pittsburgh, $84 \%$ in Eugene, and $76 \%$ in Charlottesville). Target children were on average 2.5-years-old ( $M=29.9$ months, $S D=3.2$ ) at the age 2 assessments. All steps of study recruitment, data collection, and intervention protocol received institutional review board approval.

Of the 731 original families, 677 mother-child dyads in which the primary caregiver was the biological mother were selected for the current study. This excluded families in which biological fathers $(n=12)$ were children's primary caregivers or in which children were either adopted or raised by other relatives $(n=42)$ to facilitate investigation of our main 
research questions. Children were predominantly White (50\%), African American (27\%), or biracial (14\%), and the remaining children were identified as other (e.g., Native American). Participants resided in or around three US cities: 27\% lived in Charlottesville, 38\% lived in Eugene, and 35\% lived in Pittsburgh. Mothers on average were high school graduates, but their education levels ranged from seventh grade or less to college graduates. Because this sample was derived from a prevention study, 344 families (51\%) participated in a familybased intervention.

Alternative caregivers were included at each assessment to obtain information about the child's ecology and behavior from a second informant. At the age 2 assessment, 394 alternative caregivers (58\%) participated; 53\% were biological fathers, $22 \%$ were grandmothers, $6 \%$ were mothers' boyfriends, $5 \%$ were aunts, and the remaining $14 \%$ were identified as other. These percentages remained similar at subsequent assessment times, with $45 \%$ to $53 \%$ of alternative caregivers participating, of which $39 \%$ to $46 \%$ were biological fathers, $20 \%$ were grandmothers, $9 \%$ were mothers' boyfriends, $8 \%$ were aunts, and $17 \%$ to $24 \%$ were designated as other.

\section{Procedure}

At child ages 2 to 5, the target child and birth mother, and when available, the alternate caregiver, participated in annual 2- to 3-hr assessments at the family's home. These assessments consisted of a battery of self-report measures, observational tasks, and a child testing session. This study used a subset of the collected data, which is described below. Families participating in the age 2, 3, 4, and 5 assessments were reimbursed $\$ 100, \$ 120$, $\$ 140$, and $\$ 160$, respectively.

Intervention protocol.-The Family Check-Up (FCU) is a brief, typically three-session, intervention based on motivational interviewing techniques that is designed to reduce child conduct problems by targeting parenting practices (for a complete description of the FCU, see Dishion et al., 2008). Families who were randomly assigned to the intervention condition were scheduled to meet with a parent consultant for two or more sessions, depending on the family's preference. The three meetings in which families are typically involved include an initial contact meeting, an assessment meeting, and a feedback session. For research purposes, the sequence of contacts was assessment, randomization, initial interview, and feedback session with adaptive and tailored follow-up sessions based on the needs observed in the assessment as well as the caregivers' motivation. Families in the feedback session received a \$25 gift certificate for completing the FCU and feedback session.

After the first meeting, the assessment described above, the second visit, called the "get to know you" meeting, consisted of the parent consultant meeting with the parent or parents and discussing their concerns with a focus on current family issues that were most critical to their child's and family's functioning. For the third meeting, the feedback session, parent consultants utilized motivational interviewing to summarize the results of the assessment and highlight areas of strength and areas in need of attention. Based on the results of the assessment, follow-up sessions were recommended by the parent consultant. The follow-up sessions focused on three domains of parenting: positive behavior support, healthy limit 
setting, and relationship building within a parent management training framework using a structured curriculum called Everyday Parenting (Dishion \& Stormshak, 2007; Dishion, Stormshak, \& Kavanagh, 2011). Based on the assessment, in some cases parent consultants would refer parents to other agencies for help with chronic mental health issues (substance abuse or depression in which the parent preferred medication), but in many cases such issues were managed by the parent consultant in reference to how they interfered or compromised parenting (e.g., parental depression). Caregivers in the intervention group received the FCU after each year's assessment at child ages 2, 3, 4, and 5, with 276 caregivers (80\%) participating at age 2, $242(70 \%)$ at age 3,231 (67\%) at age 4, and $202(59 \%)$ at age 5 .

\section{Measures}

Maternal depressive symptoms.-Mothers completed the 20-item Center for Epidemiological Studies Depression Scale (CES-D) at each assessment (Radloff, 1977). Items assessed a range of depressive mood symptoms such as hopelessness, poor appetite, and restless sleep. Mothers indicated the average number of days per week that they experienced symptoms using a 4-point response scale $(0=$ less than 1 day, $3=5-7$ days $)$. Items were summed to create depressive symptom scores (mean $a=0.76$ ). From ages 2 to 5 , respectively, $45 \%, 38 \%, 32 \%$, and $32 \%$ of mothers exceeded the CES-D's cutoff (i.e., 16) for clinically significant levels of depressive symptoms.

Child oppositional behavior.-Mothers and alternative caregivers rated children's oppositional behavior on multiple questionnaires. At ages 2, 3, and 4, the 99-item Child Behavior Checklist (CBCL) for Ages 1.5-5 was administered (Achenbach \& Rescorla, 2000). At age 5, the 112-item CBCL for Ages 6-18 was administered (Achenbach \& Rescorla, 2001). Two items describing oppositional behavior were consistent across both CBCLs (i.e., disobedient [at home], temper tantrums or hot tempered). Caregivers rated items based on children's behavior using a 3 -point response scale $(0=$ not true, $2=$ very true or often true).

Caregivers rated young children's disruptive behavior on the 36-item Eyberg Child Behavior Inventory (ECBI) at each assessment (Robinson, Eyberg, \& Ross, 1980). Four ECBI items that best represented child oppositionality and were not redundant with CBCL items were chosen: "Acts defiantly when told to do something," "Argues with parents about rules," "Gets angry when doesn't get own way," and "Sasses adults." ECBI items were rescaled from a 7-point Likert scale to match the 3-point scale of the CBCL. Scores were recoded so that values reflecting conceptually similar behavior frequencies were equated (i.e., 1 , or never, on the ECBI was equal to 0, or not true, on the CBCL; 2-4, or sometimes, on the ECBI was equal to 1 , or somewhat or sometimes true, on the CBCL; and 5-7, or always, on the ECBI was equal to 2, or very true or often true, on the CBCL). The $2 \mathrm{CBCL}$ items were averaged with these 4 ECBI items to create 6 -item mother-rated scales (mean $\alpha=0.78$ ) and alternative caregiver-rated scales (mean $a=0.80$ ) of children's oppositional behavior at ages $2,3,4$, and 5 .

Child IC.-Mothers and alternative caregivers rated children's self-regulation on the 13item IC subscale of the Children's Behavior Questionnaire at ages 3 and 4 (Rothbart, Ahadi, 
Hershey, \& Fisher, 2001). Items addressed self-regulatory capacities such as delaying an impulse, modulating activity level, and following directions (e.g., "Is good at following instructions" and "Is usually able to resist temptation"). The questionnaire's IC subscale is often consolidated in measures of effortful control and is widely used in developmental research on temperament (e.g., Ahadi, Rothbart, \& Ye, 1993; Olson et al., 2005). Caregivers rated items using a 7 -point Likert scale $(0=$ extremely untrue, $6=$ extremely true). Items were summed to create 13 -item mother-rated scales (mean $a=0.71$ ) and alternative caregiver-rated scales (mean $a=0.76$ ) of IC at ages 3 and 4 .

Sociodemographic covariates.-A demographics questionnaire was administered to mothers assessing family structure, parental education and income, parent criminal history, and areas of familial stress. The current study included age 2 assessments of the following variables as covariates in main analyses: child gender and race (i.e., White, Black, or other), intervention status, geographic site, and mothers' education level.

\section{Results}

\section{Data analysis plan}

We used SPSS 19.0 for preliminary analysis of descriptive statistics, intercorrelations, and missing data. We then used Mplus 5.21 with full information maximum likelihood (FIML) estimation of missing data (Muthén \& Muthén, 2007) for structural equation modeling (SEM) of three unconditional LGC models for maternal depressive symptoms and mother and alternative caregiver ratings of child oppositional behavior, as well as the following hypothesis tests:

1. Growth in maternal depressive symptoms and children's oppositional behavior from ages 2 to 5 will have correlated intercepts and correlated slopes. We estimated two parallel process LGC models to test relations between growth in maternal depression and child oppositional behavior across informants. We report unstandardized estimates to maintain their original metrics, except for correlations among growth parameters, which are standardized to help with interpretability.

2. Mothers' depressive symptoms and children's oppositional behavior will have bidirectional effects across early childhood. We estimated two fully saturated ARCL models combining maternal depressive symptoms with mother or alternative caregiver ratings of child oppositional behavior from ages 2 to 5 with correlations between variables assessed at the same age and all possible autoregressive and cross-lagged paths to account for rank order cross-time stabilities and bidirectional effects (Burkholder \& Harlow, 2003). We then pruned models by eliminating nonsignificant paths that did not worsen the overall model fit when removed, as indicated by nonsignificant chi-square difference tests. Each nonsignificant path was removed individually from the model, which was then contrasted to a nested model in which it remained to ensure the presence of other nonsignificant paths and the sequence in which they were removed did not alter final results. Eliminated paths can be inferred from 
their absence in model figures. Within-age correlations and effects of sociodemographic covariates remained in models throughout their testing but were removed from display to provide cleaner images. We report only standardized estimates of ARCL models to permit clearer interpretation of relations. All ARCL models' unstandardized estimates, standard errors, $p$ values, and standardized estimates are provided in supplemental materials available online.

3. Children's IC at ages 3 and 4 will mediate effects between maternal depressive symptoms and children's oppositional behavior across ages 2 to 5 . We added assessments of children's IC at ages 3 and 4 to ARCL models with all possible within-age correlations and paths to and from IC. We removed nonsignificant paths involving IC using the same nested modeling approach as described above. We utilized bootstrapping to test whether IC mediated effects. Bootstrapping is an iterative process of random sampling that estimates levels of significance for indirect effects and is considered a conservative but robust test of mediation (Hayes, 2009).

In accord with Kline (2005) and Bentler (2007), SEM results include model chi-square $\left(\chi^{2}\right)$, comparative fit index (CFI), root mean square error of approximation (RMSEA) and its $90 \%$ confidence interval, and standardized root mean square residual (SRMR). SRMR values $<0.10$ are considered favorable. RMSEA values $₫$. .05 indicate close approximate fit. CFI values $>0.95$ reflect good fit. We estimated all models with and without sociodemographic covariates (i.e., child gender and race, intervention group, geographic site, and maternal education level) to ensure that they had minimal effects.

\section{Preliminary analyses}

Descriptive statistics.-Table 1 presents means, standard deviations, and intercorrelations of major study variables. Means for maternal depressive symptoms decreased from child ages 2 to 5 , corroborating normative patterns of decline for depressive symptoms among parents of young children, including low-income families (Shaw, Bell, \& Gilliom, 2000). Although alternative caregiver ratings of oppositional behavior were slightly lower than maternal ratings at each age, similar decreases were observed for both mother and alternative caregiver ratings of children's oppositional behavior from toddlerhood to the early school years. Means for children's IC increased from ages 3 to 4 according to both informants, consistent with observed patterns of development of IC in early childhood (Kochanksa et al., 1996, 1997). Most assessments of maternal depression and child behavior were correlated as expected. Skewness and kurtosis values of major study variables indicated normal distributions.

Missing data and attrition.-We examined patterns of missing data and attrition to ensure they occurred at random, which is an assumption of FIML, our missing data estimator in SEM. Little's missing completely at random test with expectation maximization was not significant, $\chi^{2}(1,352)=1,435.35, p=.059$, indicating that data were missing completely at random (Little, 1988). We compared participants in the attrition group to those who continued to participate on all study variables. When children were 5 years old, 106 
mother-child dyads (16\%) did not participate in data collection. The only difference we found was that the attrition group had mothers with lower levels of education when children were 2 years old compared to mothers who continued to participate $(p<.001)$. No other pattern of systematic missing data was observed; therefore, conditions did not violate assumptions underlying use of FIML to estimate missing data in SEM.

LGC models.-We achieved the best fitting unconditional LGC model of maternal depressive symptoms by estimating an intercept and slope, and fixing their correlation to zero, $\chi^{2}(6, N=676)=6.65, p=.354$; CFI $=0.999$, RMSEA $=0.01(0.00,0.05)$, SRMR = 0.03 . Means of the intercept $\left(a_{\mathrm{i}}=16.49, S E=0.38\right)$ and slope $\left(\alpha_{\mathrm{s}}=-0.61, S E=0.16\right)$ were significant $(p<.001)$, indicating that mothers reported initial levels of depressive symptoms that were close to the CES-D's clinical cutoff (i.e., 16) when children were 2 years old, and their symptoms linearly decreased until children were 5 years old. Variances of the intercept $\left(\sigma_{\mathrm{i}}^{2}=53.99, S E=4.44\right)$ and slope $\left(\sigma_{\mathrm{S}}^{2}=3.07, S E=0.82\right)$ were significant $(p<.001)$, indicating that mothers differed in initial levels of depressive symptoms and their rate of change over time.

We then tested unconditional LGC models of children's oppositional behavior using mother and alternative caregiver ratings. A poor-fitting but acceptable model with mother ratings was identified by estimating an intercept and slope, and fixing variances of residual disturbances of repeated measures to be of equal value, $\chi^{2}(8, N=677)=53.42, p<.001$; $\mathrm{CFI}=0.95, \mathrm{RMSEA}=0.09(0.07,0.12), \mathrm{SRMR}=0.10$. Means of the intercept $\left(\alpha_{\mathrm{i}}=1.21\right.$, $S E=0.01)$ and slope $\left(a_{\mathrm{s}}=-0.06, S E=0.01\right)$ were significant $(p<.001)$. According to mothers, children's oppositional behavior declined from ages 2 to 5 . Variances of the intercept $\left(\sigma_{\mathrm{i}}^{2}=0.08, S E=0.01\right)$ and slope $\left(\sigma_{\mathrm{S}}^{2}=0.01, S E=0.001\right)$ were significant $(p$ $<.001$ ), indicating that children differed in initial levels of oppositional behavior and their rate of change from ages 2 to 5 . The intercept and slope were not correlated $(r=.12, S E=$ $0.12, p=.287$ ), thus initial levels of oppositionality were unrelated to rate of change.

We identified a close fitting LGC model with alternative caregiver ratings of oppositional behavior by estimating an intercept and slope, $\chi^{2}(5, N=571)=2.35, p=.800 ; \mathrm{CFI}=1.00$, RMSEA $=0.00(0.00,0.04)$, SRMR $=0.02$. Significant means of the intercept $\left(a_{i}=0.95\right.$, $S E=0.02, p<.001)$ and slope $\left(a_{\mathrm{s}}=-0.03, S E=0.01, p=.002\right)$ indicated a decrease in oppositional behavior from ages 2 to 5 . Significant variances of the intercept $\left(\sigma_{\mathrm{i}}^{2}=0.07, S E\right.$ $=0.01, p<.001)$ and slope $\left(\sigma_{\mathrm{S}}^{2}=0.01, S E=0.003, p=.040\right)$ indicated that children differed in initial levels of oppositional behavior and their rate of change over time. The intercept and slope were unrelated $(r=-.24, S E=0.20, p=.365)$. Unconditional LGC models for maternal depressive symptoms and child oppositional behavior demonstrated decreasing trajectories from ages 2 to 5 .

\section{Primary analyses}

Hypothesis 1: Growth in maternal depressive symptoms and children's oppositional behavior from ages 2 to 5 will have correlated intercepts and correlated slopes. 
Parallel process LGC models.: We tested the first hypothesis by estimating a parallel process LGC model with mother ratings from the first two previously reported LGC models and within-time covariances among residual disturbance terms of repeated measures that accounted for identical assessment times. An acceptable model fit was achieved, $\chi^{2}(22, N=$ $677)=71.68, p<.001 ; \mathrm{CFI}=0.97, \mathrm{RMSEA}=0.06(0.04,0.07)$, SRMR $=0.06$. Means of the intercept $\left(a_{i m}=16.46, S E=0.38\right)$ and slope $\left(a_{\mathrm{sm}}=-0.61, S E=0.16\right)$ for maternal depressive symptoms and the intercept $\left(a_{i c}=1.21, S E=0.01\right)$ and slope $\left(a_{\mathrm{sc}}=-0.06, S E=\right.$ $0.01)$ for children's oppositional behavior were significant $(p<.001)$, indicating that both linearly decreased from ages 2 to 5 . Variances also were significant $(p s<.001)$. In partial support of our hypothesis, intercepts for maternal depressive symptoms and child oppositional behavior were positively correlated $(r=.35, S E=0.07, p<.001)$. Mothers with high initial levels of depressive symptoms had children with high initial levels of oppositional behavior. Contrary to our hypothesis, slopes for maternal depressive symptoms and child oppositional behavior were unrelated $(r=.36, S E=0.23, p=.136)$. Correlations between the intercept of maternal depression and slope of child oppositional behavior $(r$ $=.16, S E=0.12, p=.196)$ and between the slope of maternal depression and intercept of child oppositionality were not significant $(r=.11, S E=0.14, p=.410)$.

We then estimated a parallel process LGC model substituting mother ratings of child oppositional behavior with alternative caregiver ratings. A model with a close approximate fit was identified, $\chi^{2}(19, N=676)=22.64, p=.254$; CFI $=0.996$, RMSEA $=0.02(0.00$, $0.04)$, SRMR $=0.03$. Means of the intercept $\left(a_{i m}=16.46, S E=0.38\right)$ and slope $\left(a_{\mathrm{sm}}=\right.$ $-0.59, S E=0.16)$ for maternal depressive symptoms and the intercept $\left(a_{i c}=0.95, S E=\right.$ $0.02)$ and slope $\left(\mathrm{a}_{\mathrm{sc}}=-0.03, S E=0.01\right)$ for children's oppositional behavior were significant $(p<<.01)$, indicating linear decreases from ages 2 to 5 . Variances of growth parameters were significant ( $p s<.05$ ). In partial support of our hypothesis, intercepts for maternal depressive symptoms and child oppositional behavior were positively correlated $(r$ $=.22, S E=0.11, p=.043)$; however, their slopes were unrelated $(r=.19, S E=0.32, p$ $=.553)$. Correlations between the intercept of maternal depressive symptoms and slope of children's oppositionality $(r=.03, S E=0.16, p=.835)$ and between the slope of maternal depression and intercept of child oppositional behavior were not significant $(r=.08, S E=$ $0.19, p=.695)$. Results of both parallel process LGC models remained significant after entering sociodemographic covariates. We partially confirmed our first hypothesis that the intercepts of maternal depressive symptoms and child oppositional behavior would be positively correlated, but we did not find support for the hypothesized relation between their slopes.

Hypothesis 2: Mothers' depressive symptoms and children's oppositional behavior will have bidirectional effects across early childhood.

Fully ARCL models.: We tested our second hypothesis with two fully ARCL models combining maternal depressive symptoms with either mother or alternative caregiver ratings of child oppositional behavior. As shown in Figure 1, we estimated an ARCL model of maternal depressive symptoms and mother-rated child oppositional behavior with a close approximate fit (see online only Supplementary Materials Table S.1). As hypothesized, we 
found bidirectional effects from ages 2 to 3 . High levels of mothers' depressive symptoms and children's oppositional behavior at age 2 predicted high levels of one another a year later. Children's oppositional behavior at age 3 predicted high levels of mothers' depressive symptoms at age 4 . Maternal depressive symptoms at age 4 predicted high levels of child oppositional behavior at age 5 . Child oppositional behavior at age 2 predicted high levels of maternal depressive symptoms at age 5; however, when estimating a fully saturated model (i.e., with all possible paths), this effect only reached marginal significance $(b=2.00, S E=$ $1.15, \beta=0.07, p=.082$ ). Although not shown in Figure 1, maternal depression and child oppositionality were positively correlated within each age (mean $r=.20, S E=0.04, p \mathrm{~s}$ $<.01$ ). Supporting our hypothesis, we found bidirectional effects from ages 2 to 3 , along with effects of children's oppositional behavior on mothers' depressive symptoms from ages 3 to 4 , maternal depressive symptoms on children's oppositional behavior from ages 4 to 5 , and children's oppositional behavior on mothers' depressive symptoms from ages 2 to 5 .

As illustrated in Figure 2, we estimated a second ARCL model with a close approximate fit using alternative caregiver ratings of child oppositional behavior (see online only Supplementary Materials Table S.2). Consistent with the previous model, we found bidirectional effects between maternal depressive symptoms and child oppositional behavior from ages 2 to 3 . We replicated effects of maternal depressive symptoms on child oppositional behavior from ages 4 to 5, and children's oppositional behavior on mothers' depressive symptoms from ages 2 to 5 . In contrast to the previous model, there was no evocative effect of child oppositional behavior on maternal depressive symptoms from ages 3 to 4 , and maternal depressive symptoms and child oppositional behavior were only correlated at age $3(r=.15, S E=0.05, p=.005)$. Both ARCL models supported our second hypothesis by demonstrating bidirectional effects between maternal depressive symptoms and children's oppositional behavior from ages 2 to 3, with a less consistent pattern of reciprocal relations up to age 5 . The only discrepancies that emerged when we estimated a fully saturated model was a marginally significant effect of maternal depression on child oppositional behavior from ages 4 to $5(b=0.004, S E=0.002, \beta=0.10, p=.083)$ and a marginally significant lagged effect of oppositional behavior from ages 2 to 5 ( $b=0.14, S E$ $=0.08, \beta=0.13, p=.070$ ). Although fully saturated and final models had discrepant levels of significance for some effects, these effects remained significant at trend levels, were replicated by the other informant, and therefore were retained in final models.

Hypothesis 3: Children's IC at ages 3 and 4 will mediate effects between maternal depressive symptoms and children's oppositional behavior across ages 2 to 5 .

Mediation models.: To test our third hypothesis, assessments of child IC at ages 3 and 4 were entered into final ARCL models. As presented in Figure 3, a mediation model of maternal depressive symptoms, mother-rated oppositional behavior, and alternative caregiver-rated IC produced a close approximate fit (see online only Supplementary Materials Table S.3). All effects between maternal depression and mother-rated child oppositional behavior presented in our first ARCL model (i.e., Figure 1) remained significant after entering mother ratings of children's IC, except for the evocative effect of age 2 oppositional behavior on maternal depression at age $5(b=1.77, S E=1.01, \beta=0.06, p$ 
$=.079)$, which we removed from the mediation model. To avoid redundancy, we only address significant paths involving IC. As highlighted in Figure 3, bootstrapping indicated an indirect effect of children's oppositional behavior on mothers' depressive symptoms from ages 2 to 5 mediated by children's IC at ages 3 and 4 ( $b=0.29, S E=0.15, \beta=0.01, p$ $=.051)$. Consistent with our hypothesis, children's oppositional behavior at age 2 was negatively related to IC at age 3, which was stable to age 4 and, in turn, negatively related to maternal depression at age 5. The direct effect of children's oppositonality on maternal depression from ages 2 to 5 was only marginally significant when considering IC, suggesting that IC at ages 3 and 4 fully mediated this effect. In addition, low levels of children's IC at age 3 predicted greater oppositionality at age 4 . IC was only correlated with oppositional behavior $(r=-.24, S E=0.05, p<.001)$ and maternal depression $(r=-.20, S E$ $=0.05, p<.001)$ at age 3 . When estimating a fully saturated mediation model, the mediated pathway from children's oppositional behavior to maternal depression from ages 2 to 5 was marginally significant $(b=0.32, S E=0.17, \beta=0.01, p=.062)$.

The next mediation model we estimated produced a close approximate fit with maternal depressive symptoms and alternative caregiver ratings of children's oppositional behavior and IC (see Figure 4 and online only Supplementary Materials Table S.4), and replicated most effects from our second ARCL model (i.e., Figure 2), except for the effect of oppositional behavior at age 2 on maternal depression at age $5(b=2.04, S E=1.20, \beta=$ $0.07, p=.089)$. Again, this effect was removed from the mediation model. Consistent with our hypothesis and previous model, bootstrapping indicated a significant indirect pathway from children's oppositional behavior at age 2 to maternal depression at age 5 via IC at ages 3 and 4 ( $b=0.40, S E=0.19, \beta=0.01, p=.031$; see dashed path in Figure 4). As expected, children's oppositional behavior at age 2 was negatively related to IC at age 3 , which was stable to age 4 and negatively associated with maternal depression at age 5 . The marginal direct effect of age 2 oppositional behavior on maternal depression at age 5 suggests this effect was fully mediated by children's IC at ages 3 and 4 . In addition, low levels of children's IC at ages 3 and 4 predicted high levels of oppositionality at ages 4 and 5, respectively. Child IC was negatively correlated with oppositional behavior $(r=-.42, S E=$ $0.04, p<.001)$ and maternal depression at age $3(r=-.19, S E=0.05, p<.001)$, but at age 4 , IC was only correlated with oppositional behavior $(r=-.41, S E=0.05, p<.001)$. The main discrepancies that arose when estimating a fully saturated model was a significant effect of children's oppositionality at age 2 on maternal depression at age $5(b=2.64, S E=1.34, \beta=$ $0.09, p=.049)$ and a nonsignificant effect of maternal depression at age 4 on children's oppositional behavior at age $5(b=0.004, S E=0.002, \beta=0.09, p=.123)$.

Finally, as shown in Figure 5, we estimated a mediation model that included maternal depressive symptoms, alternative caregiver ratings of children's oppositional behavior, and mother ratings of IC (see online only Supplementary Materials Table S.5). All effects between maternal depressive symptoms and alternative caregiver ratings of child oppositional behavior presented in our second ARCL model remained significant after entering children's IC at ages 3 and 4. Supporting our hypothesis, bootstrapping showed a significant indirect pathway from maternal depression at age 2 to child oppositional behavior at age 4 via IC at age $3(b=0.001, S E=0.000, \beta=0.02, p=.046$; see dashed path in Figure $5)$. Maternal depression at age 2 was negatively related to children's IC at age 3 , which in 
turn was negatively associated with oppositional behavior at age 4 . In addition, high levels of oppositional behavior at age 2 predicted low levels of IC at age 3, high levels of maternal depression at age 3 predicted low levels of IC at age 4, and IC was correlated with oppositional behavior and maternal depression at ages 3 and 4 (mean $r=.16, S E=0.05, p \mathrm{~s}$ $<.01)$. The main discrepancies that emerged when estimating a fully saturated model were marginally significant effects of oppositional behavior at age 2 on maternal depression at age $5(b=2.59, S E=1.37, \beta=0.09, p=.059)$, maternal depression at age 4 on child oppositional behavior at age $5(b=0.01, S E=0.002, \beta=0.12, p=.057)$, and the lagged effect of oppositional behavior from ages 2 to $5(b=0.14, S E=0.08, \beta=0.13, p=.058)$. Although fully saturated and final mediation models differed in levels of significance for some effects, most discrepancies involved the effect of age 2 oppositionality on maternal depression at age 5 , which we found fully mediated by IC at ages 3 and 4 . In sum, mediation models supported our third hypothesis that children's IC would mediate evocative effects of oppositional behavior on maternal depression across ages 2 and 5, as well as indirect effects of maternal depression on children's oppositional behavior from ages 2 to 4 .

Although not a focus of the study, we identified one consistent intervention effect across ARCL models. Consistent with a previously published paper using our data set (Shaw, Connell, Dishion, Wilson, \& Gardner, 2009), assignment to the FCU intervention significantly predicted fewer maternal depressive symptoms at the age 3 assessment ( $b s=$ -1.93 to $-1.63, S E \mathrm{~s}=0.80, \beta \mathrm{s}=-0.09$ to $-0.07, p \mathrm{~s}<.05)$.

\section{Discussion}

The current study examined bidirectional processes involving maternal depression and child oppositional behavior during early childhood in a racially diverse sample of low-income families from three US cities. A series of models using ratings from multiple caregivers showed positive and bidirectional associations between mothers' depressive symptoms and children's oppositional behavior from ages 2 to 3 , with a less consistent pattern of reciprocal relations up to age 5. Across models, child IC mediated mother-to-child effects and child evocative effects between maternal depression and child conduct problems. The present study offered methodological strengths relative to previous work, provided complementary evidence across informants of bidirectional associations between maternal depression and child oppositional behavior, and implicated children's IC as a mechanism of mother-child reciprocal effects.

\section{Parallel growth of maternal depression and child oppositional behavior}

Analyses exploring the parallel growth of maternal depressive symptoms and child oppositional behavior partially supported the hypothesis that initial levels and growth in these dimensions would be positively correlated. Consistent with previous research (Gross, Shaw, Moilanen, Dishion, \& Wilson, 2008) and corroborated by two informants, children with greater oppositional behavior at age 2 had mothers with higher concurrent levels of depressive symptoms. With respect to changes over time, decreases in oppositional behavior and maternal depressive symptoms from ages 2 to 5 were unrelated. Although unexpected, this finding is consistent with an earlier study of our sample indicating that children's 
observed noncompliance at age 2 was positively associated with mothers' initial levels of depressive symptoms but not their decrease from ages 2 to 4 (Gross, Shaw, Moilanen, Dishion, et al., 2008). The current study extends previous research by replicating associations between maternal depression and child oppositional behavior at age 2 and by showing that their decreases from ages 2 to 5 were unrelated to one another.

Mothers and alternative caregivers reported children's highest levels of oppositional behavior at the first assessment, when children were 2 years old, coinciding developmentally with rapid gains in physical and verbal capacities that facilitate autonomous behavior during toddlerhood (Dix et al., 2007; Shaw \& Bell, 1993). Mothers' depressive symptoms also peaked during this time, with almost half meeting the CES-D's criterion for clinical depression. As toddlers become more mobile and autonomous, the frequency of their oppositional behavior tends to increase (Bongers et al., 2004; Dix et al., 2007), as do mothers' efforts to socialize toddlers' understanding of social conventions and appropriate behavior (Gralinski \& Kopp, 1993). Mothers who are depressed, however, often demonstrate compromised parenting skills that increase the likelihood of child problem behavior (Goodman \& Gotlib, 1999). Mothers with depression or a susceptibility to developing depression may experience greater challenges and emotional distress than do healthier mothers when attempting to respond flexibly to toddlers' increasing oppositionality. A poor match between a depressed caregiver and hard-to-manage toddler may hinder early socialization processes, leading to stressful caregiving experiences that further exacerbate maternal depression and child problem behavior (Mangelsdorf et al., 1990).

\section{Bidirectional associations between maternal depression and child oppositional behaviors}

ARCL models supported our hypothesis of bidirectional effects between maternal depression and child oppositional behavior from ages 2 to 3. Although mothers' ratings of child oppositionality at age 3 predicted more of their depressive symptoms at age 4 , this effect was not replicated with alternative caregiver ratings, suggesting it might have been inflated by mothers' reporting bias. However, maternal depression at age 4 was shown according to both informants to predict high levels of child oppositional behavior at age 5 . Likewise, children's oppositional behavior at age 2 predicted high levels of maternal depression at age 5. Thus, we found cross-informant support for bidirectional associations between mother and child symptoms, and additional evidence of a child evocative effect based solely on mother report. While some evidence suggests mothers with depression provide negatively biased ratings of children's behavior (Burt et al., 2005; Goodman et al., 2011), it is also argued that maternal depression contributes to more honest and realistic appraisals of children's adjustment problems (e.g., Cummings \& Davies, 1994). Mothers might have provided more accurate ratings of children's behavior than alternative caregivers given the greater amount of time spent with their child; therefore, their perceptions of children's oppositional behavior at age 3 might have been sufficient to increase their own depressive symptoms the following year.

Other studies in the maternal depression literature have found small and/or few child evocative effects when examining children's externalizing problems broadly (Kouros \& Garber, 2010; Nicholson et al., 2011) or less frequent forms of conduct problems, such as 
physical aggression (Gross, Shaw, \& Moilanen, 2008). We focused on oppositional behavior because of its salience during toddlerhood relative to other conduct problems (Keenan \& Shaw, 1994). Results were consistent with the premise that oppositional behavior during toddlerhood and other conduct problems that frequently occur during developmental transitions exacerbate maternal depression (Shaw, Gross, et al., 2009). While some posit that reciprocal relations between maternal depression and child conduct problems are stronger during the transition to school (e.g., Jaffee \& Poulton, 2006), toddlerhood is marked by critical advances in physical, cognitive, and mental domains that mostly occur in the purview of primary caregivers (Bongers et al., 2004; Dix et al., 2007; Kochanska et al., 2000; Shaw \& Bell, 1993). Therefore, we should expect reciprocal mother-child processes to be more salient at a young age when toddlers undergo multifaceted transformations and mainly interact with mothers than during preschool or kindergarten when social-contextual changes introduce children to new social partners and settings (e.g., school).

The nature of oppositional behavior suggests its involvement in bidirectional processes in which behaviors of mothers and children are contingent on each other. Mothers must first seek compliance from children before they can be defied or opposed, and likewise, children who are oppositional can evoke a range of responses from mothers. Our results support evidence of bidirectional effects between maternal depression and boys' conduct problems (Gross, Shaw, \& Moilanen, 2008; Shaw, Gross, et al., 2009), and extend evidence of bidirectionality to boys and girls in an earlier phase of childhood, while also highlighting the importance of developmentally sensitive measurement. Consistent with previous research (Gartstein \& Fagot, 2003; Weinfield et al., 2009), maternal depression predicted high levels of disruptive behavior throughout early childhood. Peak levels of children's oppositional behavior at age 2 predicted greater maternal depressive symptoms at ages 3 and 5. Our findings suggest toddlers' oppositional behavior not only worsened mothers' immediate depressive symptoms but also exacerbated maternal depression years later, possibly through indirect pathways involving other child factors.

\section{IC as a mediator of bidirectional processes}

Our hypothesis that children's IC would mediate both mother-to-child effects and child evocative effects between maternal depression and child oppositional behavior was supported across models using mother and alternative caregiver ratings of child behavior. Alternative caregiver ratings of children's IC at ages 3 and 4 fully mediated the effect of oppositional behavior at age 2 on maternal depression at age 5 . This is the first evidence we know of showing that children's self-regulation mediates evocative effects of their problem behavior on maternal depression. Indirect effects were found regardless of which caregiver rated oppositional behavior, suggesting that toddlers' oppositionality contributed to their suboptimal self-regulation, which in turn worsened mothers' depressive symptoms. All models showed that low levels of child IC at age 3 predicted greater oppositional behavior at age 4, but it was children's self-regulation at age 4, not their oppositional behavior, that predicted more maternal depressive symptoms the following year. Given IC's role in adaptive behaviors and adjustment problems (Kochanska et al., 1996, 1997), children's difficulties inhibiting their impulses and modulating their behavior may have been more stressful for mothers than typical oppositional behaviors. Children's IC, as rated by 
alternative caregivers, mediated effects of their early oppositional behavior on mothers' depressive symptoms as expected in early childhood.

We also found that mother-reported child IC at age 3 mediated the effect of maternal depression at age 2 on child oppositional behavior at age 4 . Our findings are consistent with research linking maternal depression with children's low self-regulation (Lengua et al., 2008; Sektnan et al., 2010) and studies indicating that self-regulation mediates effects of maternal behavior on child conduct problems (Choe, Olson, \& Sameroff, 2013; Eisenberg et al., 2005; Spinrad et al., 2007). Maternal depression may hinder children's self-regulatory gains by modeling ineffective emotion regulation and by disrupting parenting; children's self-regulatory failures could then exacerbate their oppositional behavior. In addition to this indirect effect, child oppositionality at age 2 predicted low IC at age 3, and maternal depressive symptoms at age 3 predicted low child IC at age 4 . In contrast to models using alternative caregiver ratings of IC, both maternal depression and child oppositional behavior predicted mother ratings of children's IC, which subsequently predicted child oppositionality but not maternal depression. Thus, the direction of effects between maternal depression and child IC differed by informant, such that mothers' depressive symptoms predicted their worse perceptions of children's self-regulation, whereas alternative caregivers' negative views of children's self-regulation predicted more of mothers' depressive symptoms.

Consistent with a transactional framework, children actively influence the development of their self-regulation with their mothers (Cicchetti \& Tucker, 1994; Sameroff, 2009), and both maternal depression and child oppositional behavior can disrupt this transactional process. Young children's self-regulatory gains are promoted in part by caregivers' active guidance and support (Eisenberg et al., 2005; Kochanska et al., 2000; Sameroff, 2009; Sroufe, Duggal, Weinfield, \& Carlson, 2000), and in the current sample, parental use of positive behavior support has been shown to predict higher levels of IC in early childhood (Lunkenheimer et al., 2008). Mothers who are depressed, however, do not engage in supportive caregiving as frequently as healthier mothers, thereby hindering gains in young children's self-regulation and contributing to age-aberrant behavioral problems (Choe et al., 2013). Likewise, young children actively evoke caregiver support and guidance by reciprocating in social interactions, and their greater social involvement is associated with parents' sensitive caregiving (Feldman, 2007a). Children who are frequently oppositional may not evoke or assimilate regulatory support from caregivers as well as cooperative children, resulting in their relatively low or delayed self-regulatory competence. Children with good self-regulation require less external support to lower their arousal in stressful situations than do poorly regulated children, and are better at inhibiting inappropriate impulses that would otherwise exacerbate their conduct problems and mothers' depression.

Maternal emotional distress predicts low levels of parent-child reciprocity and family cohesion (Campbell et al., 2007; Feldman, 2007a), suggesting that depression disrupts mothers' competencies as reciprocal social partners. Compared to mothers who are depressed, mothers who score highly on positive affectivity show warmer and more supportive caregiving associated with infants' fewer temperament problems (Mangelsdorf et al., 1990). Mother-child synchrony, the temporal coordination of micro-level social 
behaviors underlying interpersonal interactions, is critical to young children's socialization (Feldman, 2007b). Mothers who are depressed and their infants show less reciprocal social interactions with one another than do healthier mother-child dyads, and lapses in motherchild synchrony are linked to poorer family functioning (Feldman, 2007a). Developmental risk in families is amplified by the transactional interplay between maternal depression and child self-regulatory problems, and their negative effects on mother-child synchrony (Feldman, 2007b; Mangelsdorf et al., 1990). Thus, individual differences in children's IC likely reflect the quality of mother-child dyadic functioning, as well as the degrees to which children can both evoke and cope with maternal distress.

\section{Independent growth of maternal depression and child oppositional behavior}

A compelling issue that arose from exploring the parallel growth of maternal depression and child oppositional behavior was that their changes over time were unrelated. Gross, Shaw, and Moilanen (2008) found that initial levels and growth in maternal depression and boys' aggressive behavior from ages 5 to 10 were positively correlated. Munson, McMahon, and Spieker (2001) also found that mean levels and annual variation in maternal depression and children's conduct problems were positively related. Both studies used mother ratings of their depressive symptoms and children's behavior. Gross, Shaw, and Moilanen (2008) found that only initial levels of mother and child symptoms were related, the same as was found in the current study, when they used alternative caregiver ratings of child behavior and adolescents' self-reports. Although our investigation focused on an earlier phase of development than these previous studies, we showed a positive and bidirectional association between maternal depression and toddlers' oppositional behavior and a less predictable pattern of associations later on. Our findings suggest that while static levels of maternal depression and child oppositionality may start out being related, their growth curves are unrelated to one another and influenced by other factors, such as gains in children's selfregulation.

Approximately half of our sample was randomly assigned to the FCU intervention, which has been linked to positive outcomes germane to the current study. Previous papers using our data set have shown that assignment to the FCU predicted faster decreases in children's oppositional and aggressive behavior from ages 2 to 4 (Dishion et al., 2008) and from ages 2 to 7.5, the latter in reference to both parent and teacher reports (Dishion et al., in press). Assignment to the FCU intervention also has been linked to higher levels of child IC at age 4 indirectly via improvements in parents' positive behavior support at age 3 (Lunkenheimer et al., 2008) and direct effects on faster increases in children's IC from ages 2 to 7.5 (Chang, Shaw, Dishion, Gardner, \& Wilson, in press). In the current study, we likely did not find intervention effects on child oppositional behavior or IC owing to differences in measurement of child problem behavior and the ages we considered children's selfregulation. As noted above, we did replicate an intervention effect first reported by Shaw, Connell, et al. (2009) showing that assignment to the FCU intervention predicted fewer maternal depressive symptoms when children were 3-years-old. Shaw, Connell, et al. (2009) further showed intervention effects on faster decreases in child problem behavior were mediated through improvements in maternal depression. 


\section{Limitations, strengths, and future directions}

Although the present study contributed one of the first tests of IC as a mediator between maternal depression and child conduct problems, our findings are limited in generalizability to low-income families recruited from WIC clinics. Definitive conclusions, therefore, cannot be drawn from this study's findings, which require replication in other sociodemographic populations. Another caveat was that we did not examine how maternal depression and child oppositional behavior develop in parallel with children's self-regulation and whether their changes are interrelated. A subtext throughout our discussion has alluded to how mother and child adjustment problems may disrupt gains in self-regulation in early childhood, particularly through effects on parenting mechanisms. To maintain focus of this study on bidirectional associations between maternal depression and child oppositionality, we did not examine parenting mechanisms or growth in IC, but we acknowledge that these variables likely influence one another continually throughout childhood. Future studies should explore the interrelated growth of maternal depression, parenting, child self-regulation, and conduct problems in an integrative manner that can account for bidirectional influences and interrelated changes over time. A difficult challenge to overcome in this endeavor is another limitation to the current study, the drawbacks of using informant ratings.

Our mediation models had at least two of three constructs rated by the same informant, suggesting potential problems of shared informant variance and reporter bias. Although most results were relatively consistent across mother and alternative caregiver ratings, we observed differences when switching raters, especially in mediation analyses. Researchers have emphasized the importance of acquiring data from different informants and with various methods when examining relations between maternal depression and child adjustment problems (Burt et al., 2005; Goodman et al., 2011). In particular, combining methods yields objective and comprehensive assessments of self-regulatory functioning (Rothbart \& Bates, 1998). For example, delay (e.g., the marshmallow task) and go/no-go tasks (e.g., Simon Says) capture children's attention to directives and their suppression of impulses, which are fundamental dimensions of IC (as well as effortful control and inhibition), and are sensitive to age-related gains in performance across early childhood (Diamond, 2006; Kochanska et al., 2000; Murray \& Kochanska, 2002). Future studies investigating our research questions with an array of methods, such as observations and laboratory tasks, may clarify whether informant ratings biased our results and whether they are replicable using other techniques. On a related note, although we relied on a transactional framework to guide our selection of modeling techniques, our model specification was not confirmatory but rather data driven to create parsimonious and best fitting models. Given our exploratory model specification (i.e., pruning nonsignificant effects), contrasting models with different informants, and not controlling for multiple comparisons across models, our results should be interpreted with caution until they are replicated with other samples.

Future studies that merge ARCL and parallel process LGC models (as opposed to using them separately) when examining bidirectional relations can further extend our findings. When estimating changes in maternal depression and child oppositionality, our parallel process LGC models did not consider time-specific lagged or cross-lagged effects. Although 
we identified linear decreases in maternal depression and child oppositional behavior through early childhood, these changes were not accounted for when testing bidirectional relations in ACRL models. Bivariate dual change score models (McArdle \& Prindle, 2008) estimate systematic changes with standard growth parameters while accounting for bidirectional relations via latent factors representing changes in variables across two assessments. This approach can test the degree to which maternal depression predicts children's subsequent conduct problems while considering their time-dependent changes. In contrast, autoregressive latent trajectory models (Bollen \& Curran, 2004) estimate standard growth parameters, thus considering fixed and random effects of their trajectories, while estimating time-specific lagged and cross-lagged effects between their repeated measures. Both approaches apply strengths of the LGC and ARCL models in simultaneous tests of their respective research questions regarding developmental change and bidirectional relations. Like all methods, however, they are not without their own drawbacks in terms of underlying assumptions, complexities in modeling, and heavy computational load. Nonetheless, longitudinal studies that examine developmental and bidirectional processes in an integrative manner with multiple or synthesized modeling techniques will advance the field.

\section{Conclusion}

The present study demonstrated the intervening role of IC in associations between maternal depression and young children's disruptive behavior. Although replication of our findings is needed, they have implications for treatment worth noting. First, mental health problems in mothers and children are interrelated, thus interventions should utilize family-centered treatment plans. Feske et al. (2001) recommend treatments be aligned for mothers with depression and their children to provide families more individualized care. Prior study of the current sample showed greater improvements in IC among children randomly assigned to an intervention tailored to their families (Chang et al., in press), although the intervention did not target self-regulation. In addition, improvements in maternal depression (also not directly targeted) and positive parenting were found to mediate intervention effects on children's adjustment problems (Dishion et al., 2008; Shaw, Connell, et al., 2009). Just as improvements in maternal depression predict reductions in children's problem behavior (van Loon, Granic, \& Engels, 2011), treatment of children's disruptive behavior may reduce mothers' depressive symptoms.

Second, prevention efforts administered in early childhood are imperative. Exposure to maternal depression between infancy and the preschool years has enduring consequences for children's future conduct problems (Bagner et al., 2010; Goodman et al., 2011; Shaw, Hyde, \& Brennan, 2012). Likewise, our study found long-term effects of children's oppositional behavior at age 2 on maternal depression at age 5. Moreover, we consistently found bidirectional associations between maternal depression and child oppositional behavior between ages 2 and 3, supporting prevention studies that suggest toddlerhood is an ideal time to intervene with mother-child dyads struggling with high levels of maternal depression and child disruptive behavior (Dishion et al., 2008; Shaw, Connell, et al., 2009). 


\section{Supplementary Material}

Refer to Web version on PubMed Central for supplementary material.

\section{Acknowledgments}

This research was supported by Grant 5R01DA022773-04 from the National Institute on Drug Abuse (to D.S.S.) We are appreciative of the families who participated and the many people who assisted in data collection and coding.

\section{References}

Achenbach TM, \& Rescorla LA (2000). Manual for the ASEBA Preschool Forms and Profiles. Burlington, VT: University of Vermont, Department of Psychiatry.

Achenbach TM, \& Rescorla LA (2001). Manual for ASEBA School-Age Forms \& Profiles. Burlington, VT: University of Vermont, Research Center for Children, Youth, \& Families.

Ahadi SA, Rothbart MK, \& Ye R (1993). Children's temperament in the U.S. and China: Similarities and differences. European Journal of Personality, 7, 359-377.

Bagner D, Pettit JW, Lewinsohn PM, \& Seeley JR (2010). Effect of maternal depression on child behavior: A sensitive period? Journal of the American Academy of Child \& Adolescent Psychiatry, 49, 699-707. [PubMed: 20610139]

Bell RQ (1968). A reinterpretation of the direction of effects in studies of socialization. Psychological Review, 75, 81-95. [PubMed: 4870552]

Belsky J (1984). The determinants of parenting: A process model. Child Development, 55, 83-96. [PubMed: 6705636]

Bentler PM (2007). On tests and indices for evaluating structural models. Personality and Individual Differences, 42, 825-829.

Bollen KA, \& Curran PJ (2004). Autoregressive latent trajectory (ALT) models: A synthesis of two traditions. Sociological Methods \& Research, 32, 336-383.

Bongers IL, Koot HM, van der Ende J, \& Verhulst FC (2004). Developmental trajectories of externalizing behaviors in childhood and adolescence. Child Development, 75, 1523-1537. [PubMed: 15369529]

Burkholder GJ, \& Harlow LL (2003). An illustration of a longitudinal cross-lagged design for larger structural equation models. Structural Equation Modeling, 10, 465-486.

Burt KB, Van Dulmen MHM, Carlivati J, Egeland B, Sroufe LA, Forman DR, et al. (2005). Mediating links between maternal depression and offspring psychopathology: The importance of independent data. Journal of Child Psychology and Psychiatry, 46, 490-499. [PubMed: 15845129]

Campbell SB, Matestic P, von Stauffenberg CV, Mohan R, \& Kirchner T (2007). Trajectories of maternal depressive symptoms, maternal sensitivity, and children's functioning at school entry. Developmental Psychology, 43, 1202-1215. [PubMed: 17723045]

Chang H, Shaw DS, Dishion TJ, Gardner F, \& Wilson MN (in press). Proactive parenting and children's effortful control: Mediating role of language and indirect intervention effects. Social Development.

Choe DE, Olson SL, \& Sameroff AJ (2013). Effects of early maternal distress and parenting on the development of children's self-regulation and externalizing behavior. Development and Psychopathology, 25, 437-453. [PubMed: 23627955]

Cicchetti D, \& Tucker D (1994). Development and self-regulatory structures of the mind. Development and Psychopathology, 6, 533-549.

Connell AM, \& Goodman SH (2002). The association between psychopathology in fathers versus mothers and children's internalizing and externalizing behavior problems: A meta-analysis. Psychological Bulletin, 128, 746-773. [PubMed: 12206193]

Côté SM, Vaillancourt T, Leblanc JC, Nagin DS, \& Tremblay RE (2006). The development of physical aggression from toddlerhood to pre-adolescence: A nation wide longitudinal study of Canadian children. Journal of Abnormal Child Psychology, 34, 71-85. [PubMed: 16565888] 
Cummings EM, \& Davies PT (1994). Maternal depression and child development. Journal of Child Psychology and Psychiatry, 35, 73-112. [PubMed: 8163630]

Cummings EM, Keller PS, \& Davies PT (2005). Towards a family process model of maternal and paternal depressive symptoms: Exploring multiple relations with child and family functioning. Journal of Child Psychology and Psychiatry, 46, 479-489. [PubMed: 15845128]

Deater-Deckard K, Dodge KA, Bates JE, \& Pettit GS (1998). Multiple risk factors in the development of externalizing behavior problems: Group and individual differences. Development and Psychopathology, 10, 469-493. [PubMed: 9741678]

Diamond A (2006). The early development of executive functions In Bialystok E \& Craik FIM (Eds.), Lifespan cognition: Mechanisms of change (pp. 70-95). New York: Oxford University Press.

Dishion T, Brennan LM, Shaw DS, McEachern A, Wilson MN, \& Jo B (in press). Prevention of problem behavior through annual Family Check-Ups in early childhood: Intervention effects from home to early elementary school. Journal of Abnormal Child Psychology.

Dishion TJ, Shaw DS, Connell AM, Gardner F, Weaver C, \& Wilson M (2008). The Family Check-Up with high-risk indigent families: Preventing problem behavior by increasing parents' positive behavior support in early childhood. Child Development, 79, 1395-1414. [PubMed: 18826532]

Dishion TJ, \& Stormshak EA (2007). Intervening in children's lives:An ecological, family-centered approach to mental health care. Washington, DC: American Psychiatric Association.

Dishion TJ, Stormshak EA, \& Kavanagh KA (2011). Everyday parenting: A professional's guide to building family management skills. Champaign, IL: Research Press.

Dix T, Stewart AD, Gershoff ET, \& Day WH (2007). Autonomy and children's reactions to being controlled: Evidence that both compliance and defiance may be positive markers in early development. Child Development, 78, 1204-1221. [PubMed: 17650134]

Dodge KA (1990). Developmental psychopathology in children of depressed mothers. Developmental Psychology, 26, 3-6.

Du Rocher Schudlich TD,\& Cummings EM (2007). Parental dysphoria and children's adjustment: Marital conflict styles, children's emotional security, and parenting as mediators of risk. Journal of Abnormal Child Psychology, 35, 627-639. [PubMed: 17390219]

Eisenberg N, Zhou Q, Spinrad TL, Valiente C, Fabes RA,\& Liew J (2005). Relations among positive parenting, children's effortful control, and externalizing problems: A three-wave longitudinal study. Child Development, 76, 1055-1071. [PubMed: 16150002]

Else-Quest NM, Hyde JS, Goldsmith HH, \& Van Hulle CA (2006). Gender differences in temperament: A meta-analysis. Psychological Bulletin, 132, 33-72. [PubMed: 16435957]

Feldman R (2007a). Maternal versus child risk and the development of parent-child and family relationships in five high-risk populations. Development and Psychopathology, 19, 293-312. [PubMed: 17459172]

Feldman R (2007b). Parent-infant synchrony: Biological foundations and developmental outcomes. Current Directions in Psychological Science, 16, 340-345.

Ferrer E, \& McArdle JJ (2010). Longitudinal modeling of developmental changes in psychological research. Current Directions in Psychological Science, 19, 149-154.

Feske U, Shear MK, Anderson B, Cyranowski J, Strassburger M, Matty M, et al. (2001). Comparison of severe life stress in depressed mothers and non-mothers: Do children matter? Depression and Anxiety, 13, 109-117. [PubMed: 11387730]

Gartstein MA, \& Fagot BI (2003). Parental depression, parenting and family adjustment, and child effortful control: Explaining externalizing behavior for preschool children. Applied Developmental Psychology, 24, 143-177.

Goodman SH, \& Gotlib IH (1999). Risk for psychopathology in the children of depressed parents: A developmental approach to the understanding of mechanisms. Psychological Review, 106, 458490. [PubMed: 10467895]

Goodman SH, Rouse MH, Connell AM, Broth MR, Hall CM, \& Heyward D (2011). Maternal depression and child psychopathology: A meta-analytic review. Clinical Child Family Psychology Review, 14, 1-27. [PubMed: 21052833]

Gorman-Smith D, \& Loeber R (2005). Are developmental pathways in disruptive behaviors the same for girls and boys? Journal of Child and Family Studies, 14, 15-27. 
Gralinski JH, \& Kopp CB (1993). Everyday rule for behavior: Mothers' requests to young children. Developmental Psychology, 29, 573-584.

Greenberg MT (2006). Promoting resilience in children and youth: Preventive interventions and their interface with neuroscience. Annals New York Academy of Sciences, 1094, 139-150.

Gross HE, Shaw DS, Burwell RA, \& Nagin DS (2009). Transactional processes in child disruptive behavior and maternal depression: A longitudinal study from early childhood to adolescence. Development and Psychopathology, 21, 139-156. [PubMed: 19144227]

Gross HE, Shaw DS, \& Moilanen KL (2008). Reciprocal associations between boys' externalizing problems and mothers' depressive symptoms. Journal of Abnormal Child Psychology, 36, 693709. [PubMed: 18288602]

Gross HE, Shaw DS, Moilanen KL, Dishion TJ, \& Wilson MN (2008). Reciprocal models of child behavior and depressive symptoms in mothers and fathers in a sample of children at risk for early conduct problems. Journal of Family Psychology, 22, 742-751. [PubMed: 18855510]

Hayes AF (2009). Beyond Baron and Kenny: Statistical mediation analysis in the new millennium. Communication Monographs, 76, 408-420.

Jaffee SR, \& Poulton R (2006). Reciprocal effects of mothers' depression and children's problem behaviors from middle childhood to early adolescence In Huston AC, Ripke MN, \& McCord J (Eds.), Developmental contexts in middle childhood: Bridges to adolescence and adulthood ( pp. 107-129). New York: Cambridge University Press.

Keenan K, \& Shaw DS (1994). The development of aggression in toddlers: A study of low-income families. Journal of Abnormal Child Psychology, 22, 53-77. [PubMed: 8163775]

Kessler RC, Berglund P, Demler O, Jin R, Koretz D, Merikangas KR, et al. (2003). The epidemiology of major depressive disorder: Results from the National Comorbidity Survey Replications (NCSR). Journal of American Medical Association, 289, 3095-3105.

Kline RB (2005). Principles and practice of structural equation modeling (2nd ed.). New York: Guilford Press.

Kochanska G, Murray K, \& Coy KC (1997). Inhibitory control as a contributor to conscience in childhood: From toddler to early school age. Child Development, 68, 263-277. [PubMed: 9180001]

Kochanska G, Murray KT, \& Harlan ET (2000). Effortful control in early childhood: Continuity and change, antecedents, and implications for social development. Developmental Psychology, 36, 220-232. [PubMed: 10749079]

Kochanska G, Murray K, Jacques TY, Koenig AL, \& Vandegeest KA (1996). Inhibitory control in young children and its role in emerging internalization. Child Development, 67, 490-507. [PubMed: 8625724]

Kouros CD, \& Garber J (2010). Dynamic associations between maternal depressive symptoms and adolescents' depressive and externalizing symptoms. Journal of Abnormal Child Psychology, 38, 1069-1081. [PubMed: 20607385]

Lengua LJ, Bush NR, Long AC, Kovacs EA, \& Trancik AM (2008). Effortful control as a moderator of the relation between contextual risk factors and growth in adjustment problems. Development and Psychopathology, 20, 509-528. [PubMed: 18423092]

Little RJA (1988). A test of missing completely at random for multivariate data with missing values. Journal of the American Statistical Association, 83, 1198-1202.

Loeber R, \& Farrington DP (2000). Young children who commit crime: Epidemiology, developmental origins, risk factors, early interventions, and policy implications. Development and Psychopathology, 12, 737-762. [PubMed: 11202042]

Lovejoy MC, Graczyk PA, O’Hare E, \& Neuman G (2000). Maternal depression and parenting: A meta-analytic review. Clinical Psychology Review, 20, 561-592. [PubMed: 10860167]

Lunkenheimer ES, Dishion TJ, Shaw DS, Connell AM, Gardner F, Wilson MN, et al. (2008). Collateral benefits of the family check-up on early childhood school readiness: Indirect effects of parents' positive behavior support. Developmental Psychology, 44, 1737-1752. [PubMed: 18999335] 
Mangelsdorf S, Gunnar M, Kestenbaum R, Lang S, \& Andreas D (1990). Infant proneness-to-distress temperament, maternal personality, and mother-infant attachment: Associations and goodness of fit. Child Development, 61, 820-831. [PubMed: 2364756]

Martel MM, \& Nigg JT (2006). Child ADHD and personality/temperament traits of reactive and effortful control, resiliency, and emotionality. Journal of Child Psychology and Psychiatry, 47, 1175-1183. [PubMed: 17076757]

McArdle JJ, \& Prindle JJ (2008). A latent change score analysis of a randomized clinical trial in reasoning training. Psychology and Aging, 23, 702-719. [PubMed: 19140642]

Moilanen KL, Shaw DS, Dishion TJ, Gardner F, \& Wilson M (2010). Longitudinal growth and predictors of inhibitory control in early childhood. Social Development, 19, 326-347.

Munson JA, McMahon RJ, \& Spieker SJ (2001). Structure and variability in the developmental trajectory of children's externalizing problems: Impact of infant attachment, maternal depressive symptomatology, and child sex. Development and Psychopathology, 13, 277-296. [PubMed: 11393647]

Murray KT, \& Kochanska G (2002). Effortful control: Factor structures and the relation to externalizing and internalizing behaviors. Journal of Abnormal Child Psychology, 30, 503-514. [PubMed: 12403153]

Muthén LK, \& Muthén B (2007). Mplus user's guide (Version 5.21). Los Angeles: Author.

Nagin D, \& Tremblay RE (1999). Trajectories of boys' physical aggression, opposition, and hyperactivity on the path to physically violent and nonviolent juvenile delinquency. Child Development, 70, 1181-1196. [PubMed: 10546339]

Nicholson JS, Deboeck PR, Farris JR, Boker SM, \& Borkowski JG (2011). Maternal depressive symptomatology and child behavior: Transactional relationship with continuous bidirectional coupling. Developmental Psychology, 47, 1312-1323. [PubMed: 21639624]

Olson SL, Sameroff AJ, Kerr DCR, Lopez NL, \& Wellman HM (2005). Developmental foundations of externalizing problems in young children: The role of effortful control. Development and Psychopathology, 17, 25-45. [PubMed: 15971758]

Olson SL, Schilling EM, \& Bates JE (1999). Measurement of impulsivity: Construct coherence, longitudinal stability, and relationship with externalizing problems in middle childhood and adolescence. Journal of Abnormal Child Psychology, 27, 151-165. [PubMed: 10400061]

Radloff LS (1977). The CES-D Scale: A self-report depression scale for research in the general population. Applied Psychological Measurement, 1, 385-401.

Raposa EB, Hammen CL, \& Brennan PA (2011). Effects of child psychopathology on maternal depression: The mediating role of child-related acute and chronic stressors. Journal of Abnormal Psychology, 39, 1177-1186.

Robinson EA, Eyberg SM,\& Ross AW (1980). The standardization of an inventory of child conduct problem behaviors. Journal of Clinical Child Psychology, 9, 22-28.

Rothbart MK, Ahadi SA, Hershey KL, \& Fisher P (2001). Investigations of temperament at 3-7 years: The Children's Behavior Questionnaire. Child Development, 72, 1394-1408. [PubMed: 11699677]

Rothbart MK, \& Bates JE (1998). Temperament In Damon W (Series Ed.) \& Eisenberg N (Vol. Ed.), Handbook of child psychology: Social, emotional, personality development (Vol. 3, pp. 105-176). New York: Wiley.

Sameroff AJ (2009). The transactional model of development: How children and contexts shape each other. Washington, DC: American Psychological Association.

Sameroff AJ, \& Chandler M (1975). Reproductive risk and the continuum of caretaking casualty In Horowitz FD (Ed.), Review of child development research (Vol. 4, pp. 187-244). Chicago: University of Chicago Press.

Sektnan M, McClelland MM, Acock A, \& Morrison FJ (2010). Relations between early family risk, children's behavioral regulation, and academic achievement. Early Childhood Research Quarterly, 25, 464-479. [PubMed: 20953343]

Shaw DS, \& Bell RQ (1993). Developmental theories of parental contributors to antisocial behavior. Journal of Abnormal Child Psychology, 21, 493-518. [PubMed: 8294650] 
Shaw DS, Bell RQ, \& Gilliom M (2000). A truly early starter model of antisocial behavior revisited. Clinical Child and Family Psychology Review, 3, 155-172. [PubMed: 11225751]

Shaw DS, Connell A, Dishion TJ, Wilson MN, \& Gardner F (2009). Improvements in maternal depression as a mediator of intervention effects on early childhood problem behavior. Development and Psychopathology, 21, 417-439. [PubMed: 19338691]

Shaw DS, Gilliom M, Ingoldsby EM, \& Nagin DS (2003). Trajectories leading to school-age conduct problems. Developmental Psychology, 39, 189-200. [PubMed: 12661881]

Shaw DS, Gross HE, \& Moilanen KL (2009). Developmental transactions between boys' conduct problems and mothers' depressive symptoms In Sameroff AJ (Ed.), The transactional model of human development: How children and contexts shape each other (pp. 77-96). Washington, DC: American Psychological Association.

Shaw DS, Hyde L, \& Brennan L (2012). Early predictors of boys' antisocial trajectories. Development and Psychopathology, 24, 871-888. [PubMed: 22781860]

Spinrad TL, Eisenberg N, Gaertner B, Popp T, Smith CL, Kupfer A, et al. (2007). Relations of maternal socialization and toddler's effortful control to children's adjustment and social competence. Developmental Psychology, 43, 1170-1186. [PubMed: 17723043]

Sroufe AL, Duggal S, Weinfield N, \& Carlson E (2000). Relationships, development, and psychopathology In Sameroff AJ, Lewis M, \& Miller SM (Eds.), Handbook of developmental psychopathology (2nd ed., pp. 75-91). New York: Plenum Press.

Utendale WT, \& Hastings PD (2011). Developmental changes in the relations between inhibitory control and externalizing problems during early childhood. Infant and Child Development, 20, 181-193.

Utendale WT, Hubert M, Saint-Pierre AB, \& Hastings PD (2011). Neurocognitive development and externalizing problems: The role of inhibitory control deficits from 4 to 6 years. Aggressive Behavior, 37, 476-488. [PubMed: 21721014]

van Loon LMA, Granic I, \& Engels RCME (2011). The role of maternal depression on treatment outcome for children with externalizing behavior problems. Journal of Psychopathology Behavioral Assessment, 33, 178-186. [PubMed: 21765595]

Weinfield NS, Ingerski L, \& Moreau SC (2009). Maternal and paternal depressive symptoms as predictors of toddler adjustment. Journal of Family Studies, 18, 39-47. 


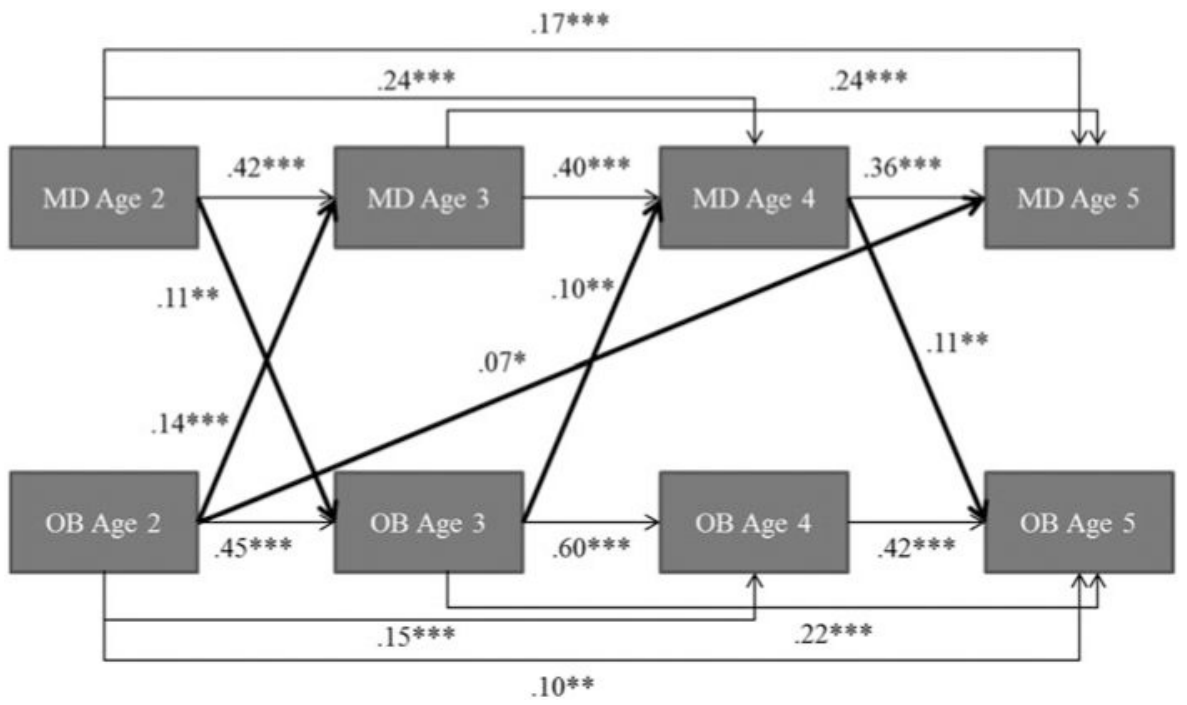

Figure 1.

Standardized solution for autoregressive cross-lagged model of maternal depressive symptoms and mother-rated child oppositional behavior: $\chi^{2}(7, N=677)=4.08, p=.771$; comparative fit index $=1.00$, root mean square error of approximation $=0.00(0.00,0.03)$, standard root mean square residual $=0.01$. Covariates are child gender, race, intervention group, geographic site, and maternal education level. Correlations not shown. $R^{2}$ s: maternal depressive symptoms age $3=.23$, maternal depressive symptoms age $4=.36$, maternal depressive symptoms age $5=.42$, mother-rated child oppositional behavior age $3=.25$, mother-rated child oppositional behavior age $4=.48$, and mother-rated child oppositional behavior age $5=.47$. $* p<.05 . * * p<.01 . * * * p<.001$. 


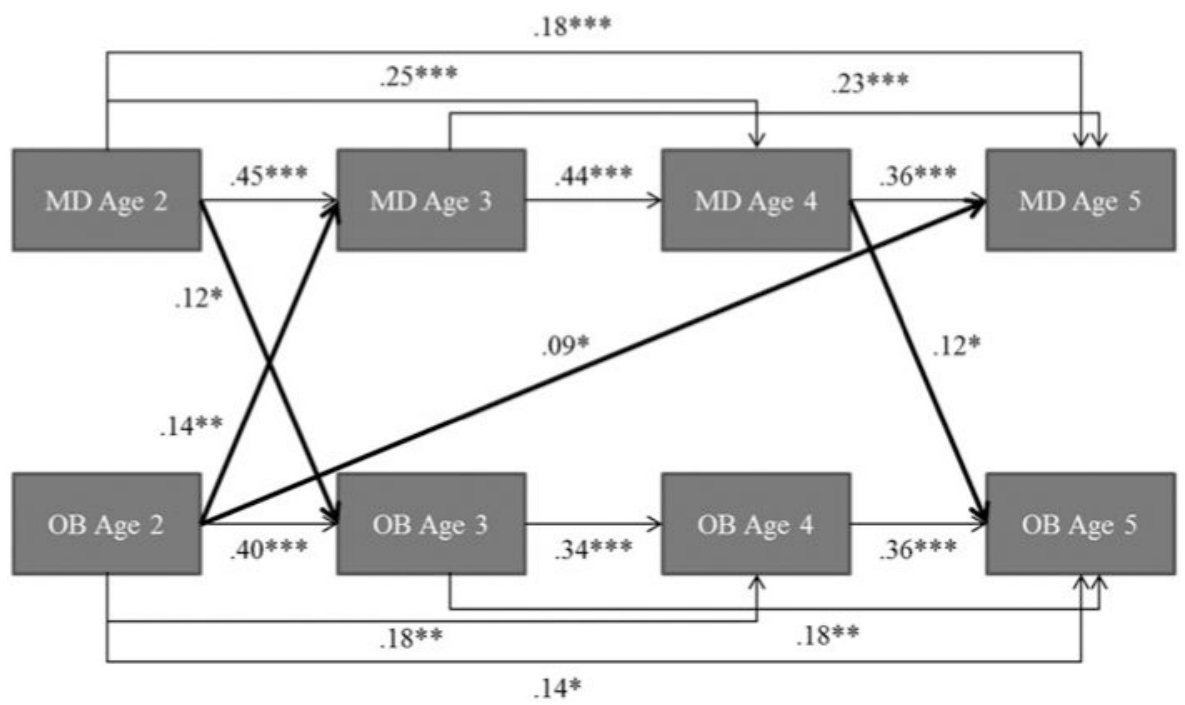

Figure 2.

Standardized solution for autoregressive cross-lagged model of maternal depressive symptoms and alternative caregiver-rated child oppositional behavior: $\chi^{2}(8, N=677)=$ $5.39, p=.715$; comparative fit index $=1.00$; root mean square error of approximation $=0.00$ $(0.00,0.03)$; standard root mean square residual $=0.01$. Covariates are child gender, race, intervention group, geographic site, and maternal education level. Correlations not shown. $R^{2}$ s: maternal depressive symptoms age $3=.23$, maternal depressive symptoms age $4=.35$, maternal depressive symptoms age $5=.43$, caregiver-rated caregiver-rated child oppositional behavior age $3=.20$, caregiver-rated child oppositional behavior age $4=.24$, and caregiverrated child oppositional behavior age $5=.33$. $* p<.05$. ${ }^{*} p<.01$. *** $p<.001$. 


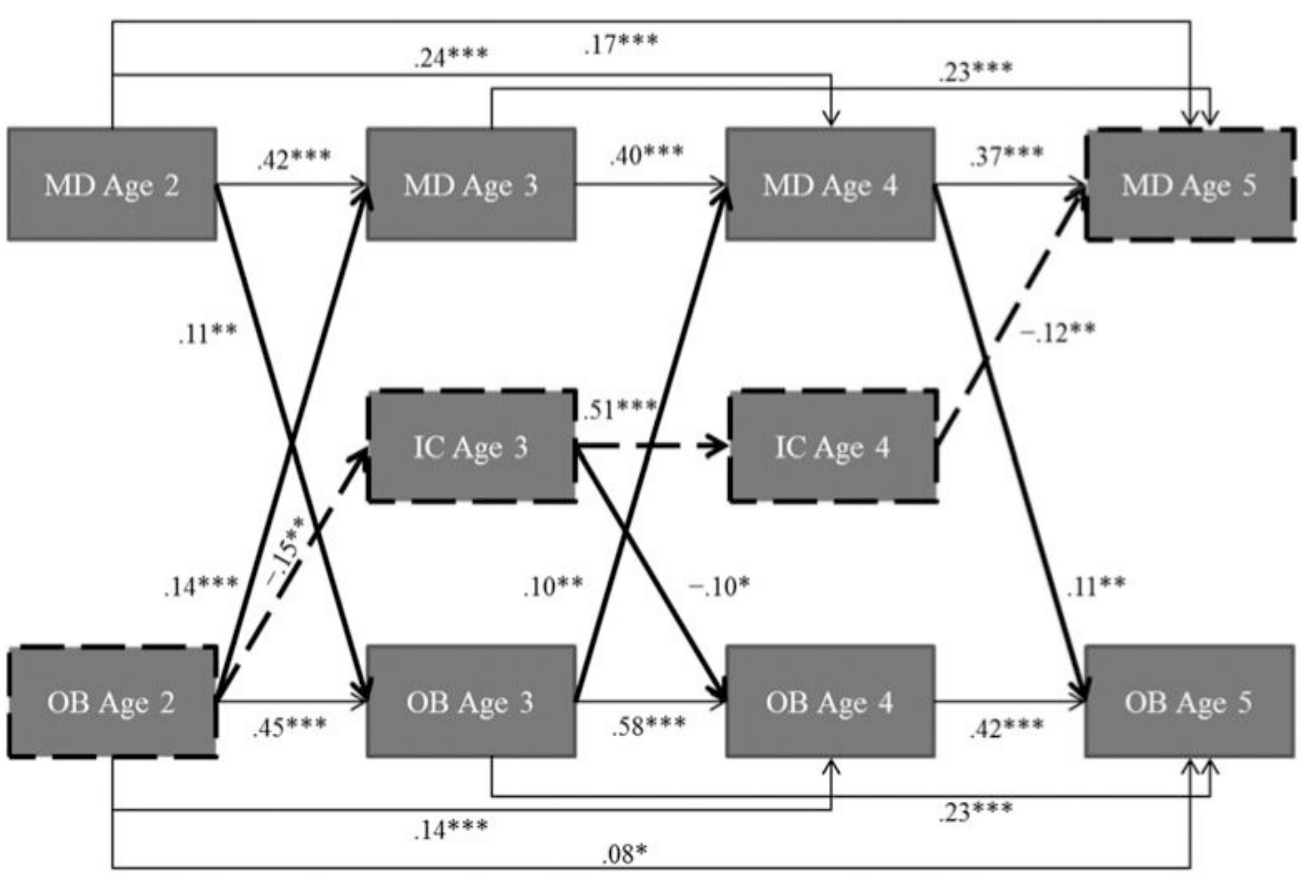

Figure 3.

Standardized solution for mediation model of maternal depressive symptoms, mother-rated child oppositional behavior, and alternative caregiver-rated inhibitory control (IC): $\chi^{2}(17, N$ $=677)=13.38, p=.711$; comparative fit index $=1.0$, root mean square error of approximation $=0.00(0.00,0.03)$, standard root mean residual $=0.02$. Significant mediation for dashed pathway, mother-rated child oppositional behavior age $2 \rightarrow$ caregiver-rated IC age $3 \rightarrow$ caregiver-rated IC age $4 \rightarrow$ maternal depressive symptoms age $5(b=0.29, S E=$ $0.15, \beta=0.01, p=.051)$. Covariates are child gender, race, intervention group, geographic site, and maternal education level. Correlations not shown. $R^{2}$ s: maternal depressive symptoms age $3=.23$, maternal depressive symptoms age $4=.36$, maternal depressive symptoms age $5=.43$, mother-rated child oppositional behavior age $3=.25$, mother-rated child oppositional behavior age $4=.48$, mother-rated child oppositional behavior age 5 $=.47$, caregiver-rated IC age $3=.05$, and caregiver-rated IC age $4=.29 .{ }^{*} p<.05 . * * p<.01$. $* * * p<.001$. 


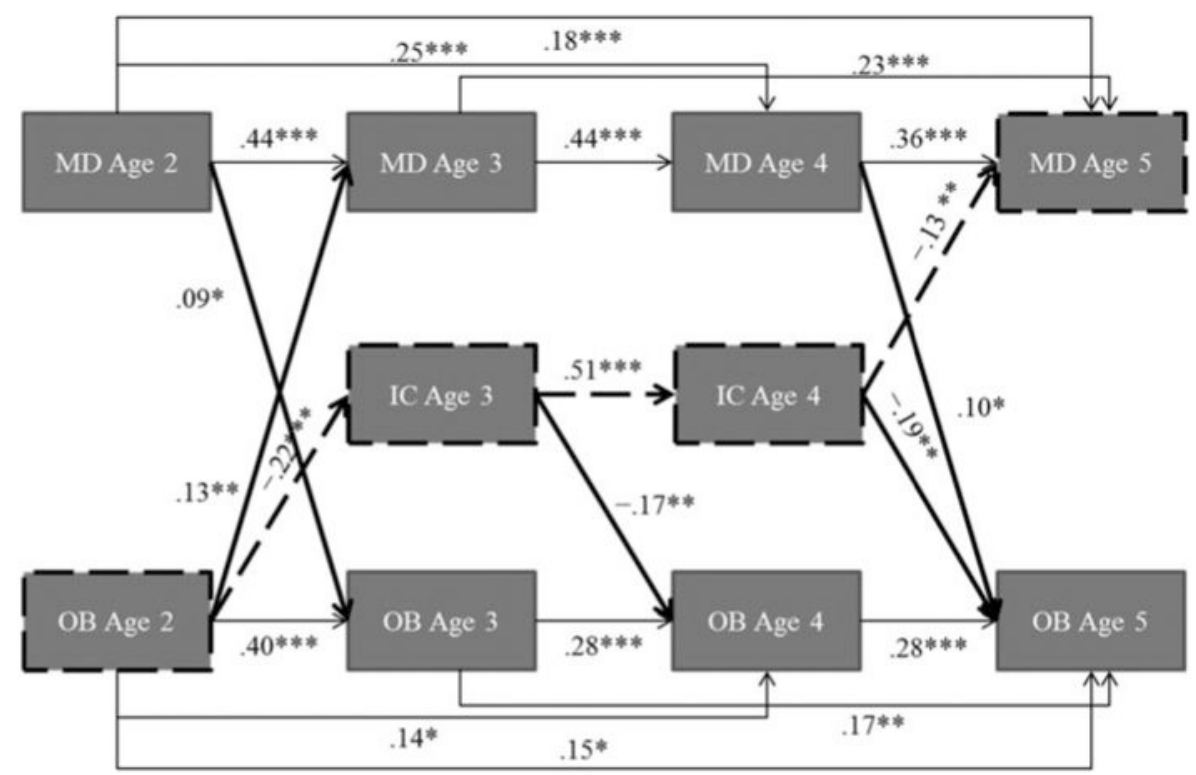

Figure 4.

Standardized solution for mediation model of maternal depressive symptoms and alternative caregiver-rated child oppositional behavior and inhibitory control (IC): $\chi^{2}(17, N=677)=$ $20.10, p=.269$; comparative fit index $=1.0$, root mean square error of approximation $=0.02$ $(0.00,0.04)$, standard root mean square residual $=0.02$. Significant mediation for dashed pathway, caregiver-rated child oppositional behavior age $2 \rightarrow$ caregiver-rated IC age $3 \rightarrow$ caregiver-rated IC age $4 \rightarrow$ maternal depressive symptoms age 5 ( $b=0.40, S E=0.19, \beta=$ $0.01, p=.031$ ). Covariates are child gender, race, intervention group, geographic site, and maternal education level. Correlations not shown. $R^{2}$ s: maternal depressive symptoms age 3 $=.22$, maternal depressive symptoms age $4=.35$, maternal depressive symptoms age 5 $=.43$, caregiver-rated child oppositional behavior age $3=.20$, caregiver-rated child oppositional behavior age $4=.25$, caregiver-rated child oppositional behavior age $5=.36$, caregiver-rated IC age $3=.09$, and caregiver-rated IC age $4=.30 .{ }^{*} p<.05 . * * p<.01 . * * * p$ $<.001$. 


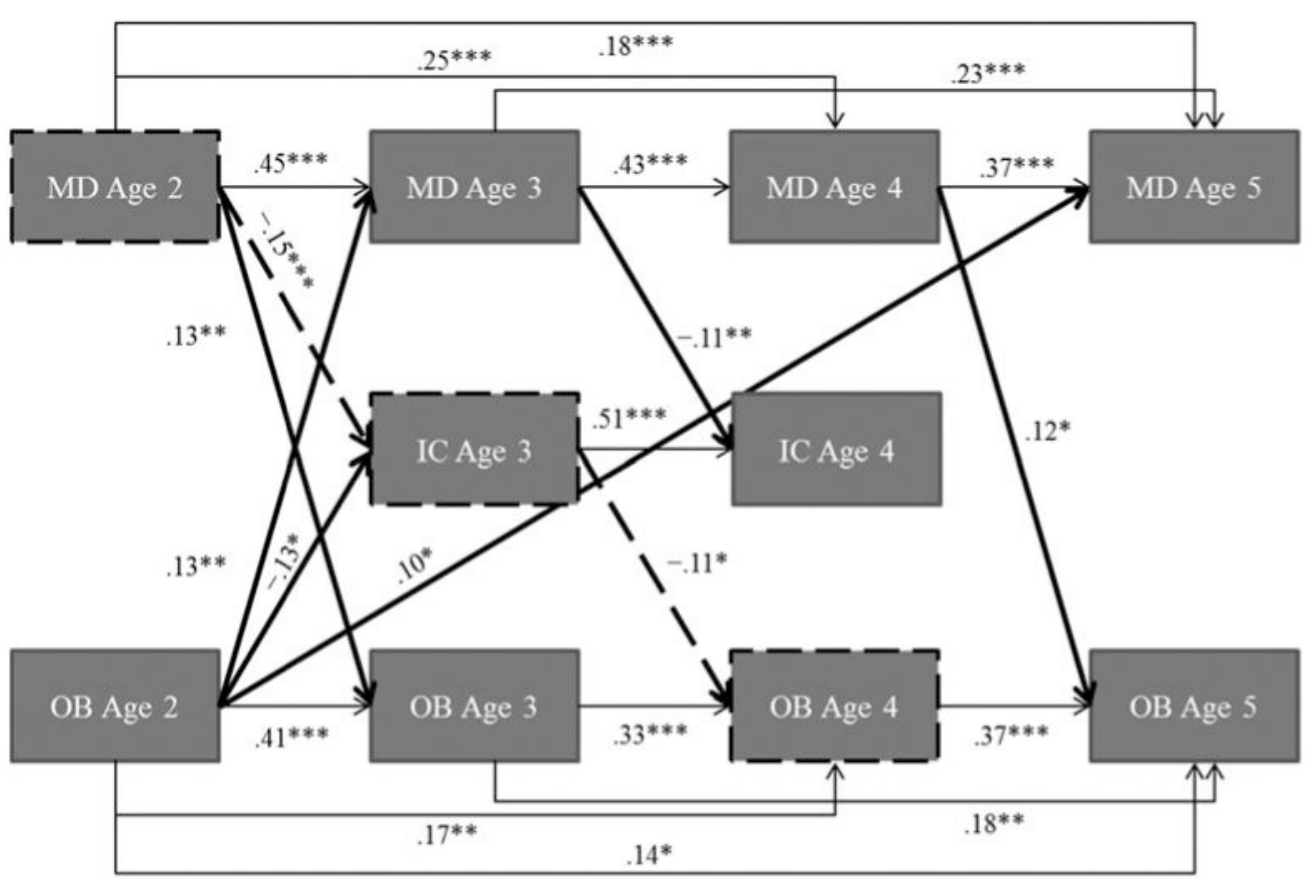

Figure 5.

Standardized solution for mediation model of maternal depressive symptoms, alternative caregiver-rated oppositional behavior, and mother-rated inhibitory control (IC): $\chi^{2}(16, N=$ $677)=11.38, p=.785$; comparative fit index $=1.0$, root mean square error of approximation $=0.00(0.00,0.02)$, standard root mean square residual $=0.01$. Significant indirect effect for dashed pathway, maternal depressive symptoms age $2 \rightarrow$ mother-reported IC age $3 \rightarrow$ caregiver-rated child oppositional behavior age 4 ( $b=0.001, S E=0.000, \beta=0.02, p=.046)$. Covariates are child gender, race, intervention group, geographic site, and maternal education level. Correlations not shown. $R^{2}$ s: maternal depressive symptoms age $3=.23$, maternal depressive symptoms age $4=.35$, maternal depressive symptoms age $5=.43$, caregiver-rated child oppositional behavior age $3=.19$, caregiver-rated child oppositional behavior age $4=.24$, caregiver-rated child oppositional behavior age $5=.33$, mother-rated IC age $3=.09$, and mother-rated IC age $4=.33 . * p<.05 . * * p<.01 . * * * p<.001$. 


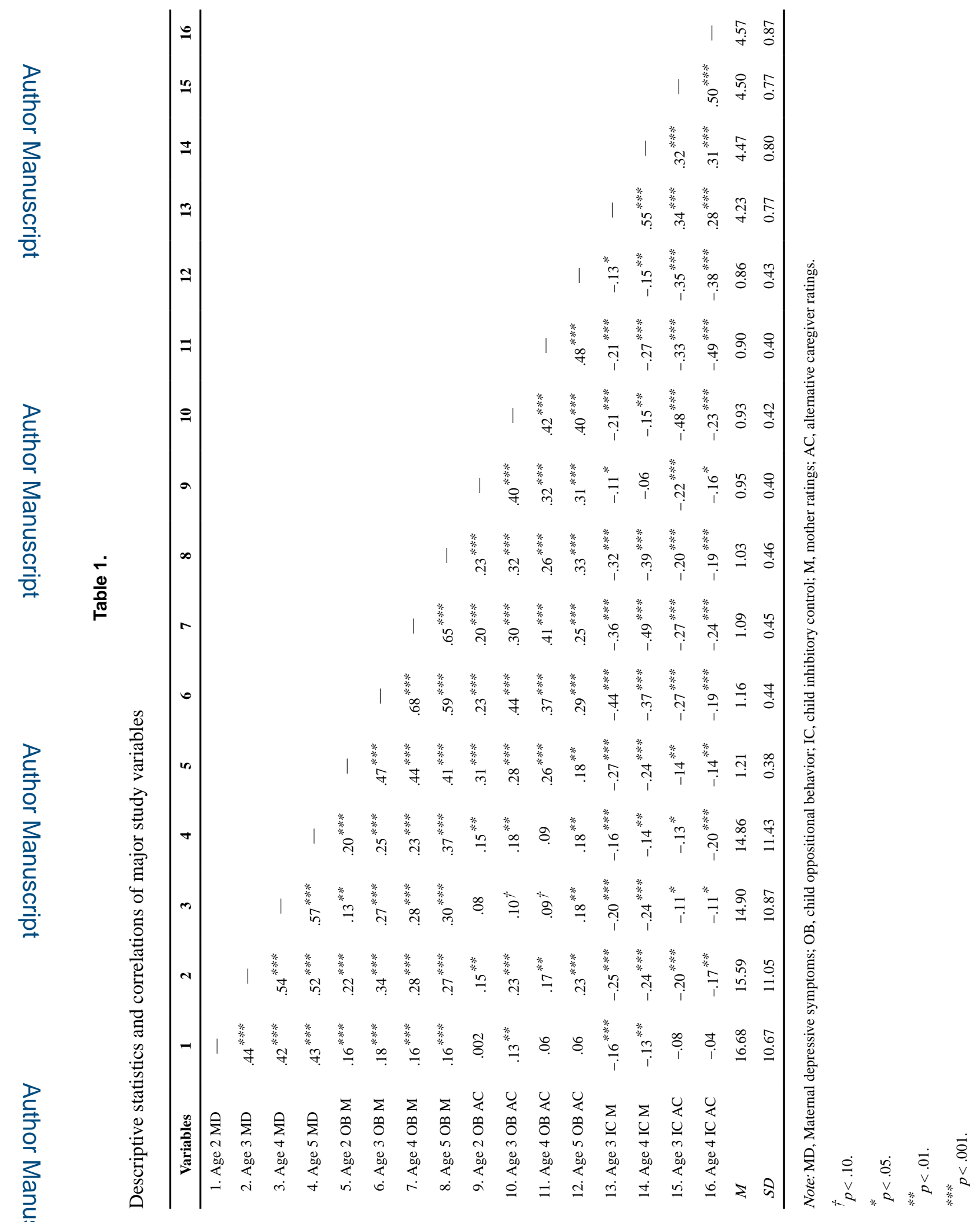

